\title{
Simulation of Policy Tools' Effects on Farmers' Adoption of Conservation Tillage Technology: An Empirical Analysis in China
}

\author{
Hongbin Liu ${ }^{1,2}$, Mengyao $\mathrm{Wu}^{1}$, Xinhua Liu ${ }^{1}$, Jiaju Gao ${ }^{1}$, Xiaojuan Luo ${ }^{3}$ and Yan $\mathrm{Wu}^{1, *}$ \\ 1 College of Land and Environment, Shenyang Agricultural University, Shenyang 110866, China; \\ liuhongbinsy@syau.edu.cn (H.L.); 2019220430@stu.syau.edu.cn (M.W.); 2020220472@stu.syau.edu.cn (X.L.); \\ 2020240452@stu.syau.edu.cn (J.G.) \\ 2 College of Public Administration, Nanjing Agricultural University, Nanjing 210095, China \\ 3 Jiangxi Economic Development Research Institute, Jiangxi Normal University, Nanchang 330022, China; \\ luoxiaojuan@jxnu.edu.cn \\ * Correspondence: 2011500017@syau.edu.cn; Tel.: +86-24-88487155
}

check for updates

Citation: Liu, H.; Wu, M.; Liu, X.; Gao, J.; Luo, X.; Wu, Y. Simulation of Policy Tools' Effects on Farmers'

Adoption of Conservation Tillage Technology: An Empirical Analysis in China. Land 2021, 10, 1075. https:// doi.org/10.3390/land10101075

Academic Editors: Jianjun Zhang, Guangqing Chi, Yongheng Rao and Feng $\mathrm{Xu}$

Received: 3 September 2021

Accepted: 10 October 2021

Published: 12 October 2021

Publisher's Note: MDPI stays neutral with regard to jurisdictional claims in published maps and institutional affiliations.

\begin{abstract}
Conservation tillage technology (CTT) provides a new solution to the problem of cultivated land protection. Using effective policy tools to ensure that farmers adopt conservation tillage technology is crucial to the sustainable utilization of cultivated land resources and the development of agricultural modernization. This study aims to explore the decision-making and the dynamic influence mechanism involved in using policy tools to influence farmers' technology adoption behaviors by constructing a theoretical framework. Based on survey data of farmers in Liaoning Province, China, the Agent Belief-Desire-Intention (BDI) model is applied. The results show that the implementation of policy tools promotes farmers' adoption of CTT, but different types of policy tools have different impacts on the decision-making behavior of farmers; a change in the intensity of the policy tools will also cause differences in farmers' behavioral responses. In addition, policy tools must be implemented in a timely manner, as the number of farmers adopting CTT reaches the maximum within 2-3 years. Based on the above research results, in order to effectively promote farmers' adoption of CTT, the government should pay attention to the role of information-inducing policy and set flexible policy subsidies and punishment standards.
\end{abstract}

Keywords: conservation tillage technology; farmers' technology adoption behavior; policy tools; agent model; BDI structure

\section{Introduction}

Cultivated land resources are essential for human survival and production and a non-renewable natural resource [1]. In recent years, due to long-term and intensive development and utilization, the amount and quality of cultivated land have decreased significantly, which poses a serious threat to the comprehensive grain production capacity and the sustainable development of agriculture [2]. To effectively improve the ecological resources and resolve environmental problems associated with cultivated land, the Central Government of the People's Republic of China emphasizes the innovation of the ecological and environmental protection system, and the formulation and implementation of policy tools, as the means and measures to solve such problems are crucial [3]. In the context of cultivated land resources protection, conservation tillage has become an important tool, and a major national strategy [4]. CTT originated in the United States and developed rapidly after being introduced in China in the 1960s [4,5]. It is generally defined internationally as the use of tillage technology to cover the ground with a large volume of straw residue, restricting tillage to the period of guaranteed seed germination, and mainly uses pesticides to control weeds, diseases, and pests [6,7]. Conservation tillage takes mechanized equipment as the carrier, and straw residue mulching, tillage reduction, and no-tillage sowing 
technology are its core principles. It has the effects of improving soil quality and protecting the farmland ecological environment [8-11]. However, the transformation of the agricultural production model is not easy. On the one hand, the implementation of CTT is strictly dependent on the guidance and support of national policies [12]; on the other hand, farmers are not only the direct users of cultivated land and the implementers of farming technology, but also the recipients of policies. The promotion of technology also requires the active participation of farmers [13]. Since the beginning of the 21st century, the No. 1 Document of the Central Committee of the Communist Party of China has repeatedly proposed and encouraged the implementation of conservation farming; the central government has made several investments to increase subsidies for the purchase of agricultural machinery; at the same time, the Ministry of Agriculture and other relevant departments have successively introduced straw burning control and reductions in pesticide and fertilizer usage. Such policies encourage farmers to shift away from traditional farming behaviors [12,14]. Under the combined effect of multiple policy tools, in 2017, the conservation tillage area in China accounted for $5.62 \%$ of the total cultivated land area. However, the implementation of the technology has not achieved the designated target; there is still considerable room for development [4]. Therefore, research on farmers' behavior and policy tools has attracted the attention of academics and politicians [14], and it is of great significance to explore the influence mechanism between policy tools and farmers' technology adoption behavior.

At present, the existing literature mainly focuses on the following aspects. In terms of conservation tillage, research has focused on the benefits of conservation tillage $[8,15,16]$, the status quo of its implementation, and the problems with its extension [4,9-11], etc. The results show that it is of great significance to the improvement of cultivated land quality and grain yield. However, there are still obstacles to the implementation and promotion of this technology. In terms of farmer behavior, the existing results mostly discuss the factors influencing technology adoption behavior in terms of internal and external factors. The results show that farmer behavior is affected by internal characteristics and external key factors [17-20]. In terms of policy tools, scholars often study the impact of policy tools on macro land use changes [21-24] or explore a specific incentive policy [25-28]; some scholars also research the effect of policy stimuli, proving that policies can effectively stimulate farmers' behavior $[14,22,27,28]$. In terms of the use of research methods, generally, simple linear regression models such as logistic regression [29] or structural equation models [30] are used for quantitative analysis. Although the existing literature has been studied in depth, several aspects can be improved. The existing research focuses on the micro-level of farmers, and there is little research on the influence mechanism of multiple policy tools and dynamic changes in farmers' behavior at the micro level. In terms of research content, the existing research lacks a reasonable description of the overall decision-making process of farmers and an analysis of the decision-making mechanism of farmers. Moreover, under the effect of different policy tools, the exploration of the decision-making process involved in farmers' behavior is insufficient. In terms of research methods, existing studies by most scholars use simple quantitative models to analyze the decision-making mechanism of farmers' behavior, but farmers' decision-making processes have the characteristics of being nonlinear, complex, and dynamic [17-20,29-31]. It is difficult to reflect the complex decision-making process of farmers by applying simple linear regression models and quantitative analysis; a combination with the dynamic simulation model method needs to be considered.

In summary, this study will clarify the decision-making process involved in farmers' CTT adoption behavior under the influence of different policy tools based on the Agent Belief-Desire-Intention (BDI) model structure. The policy tools considered in this study can be divided into three types: information-induced, fund-subsidy, and controlconstrained. The structure of the Agent BDI model can reasonably describe the behavior of farmers through their beliefs, desires, and intentions, and portray the complex relationships between farmers and their dynamic decision-making process [32-37]. A theoretical analysis framework for farmers' technology adoption behavior is constructed. Taking 
CTT as an example, using the Liaoning Provincial Statistical Yearbook and 364 micro survey data of farmers for empirical analysis, multiple linear regression models and Agent simulation modeling methods are combined to construct a simulation model of farmers' adoption behavior regarding CTT. Using the NetLogo 6.2.0 simulation platform, we design and implement simulation scenarios for the information-induced, fund-subsidy, and control-constrained policy tools, and we explore the dynamic impact of them on farmers' technology adoption behavior under different implementation intensities. This reveals their behavioral impact mechanisms. In theory, this study enriches the CTT research content by using a combination of econometrics and simulation models to study farmers' adoption of CTT, move from qualitative analysis to dynamic analysis from the perspective of complex systems, clarify the mechanism and direction of the impact of multiple policy tools, and provide new research ideas. In practice, the study is expected to offer a theoretical basis for formulating diverse and flexible related policies, optimize targeted policy tools to effectively increase the enthusiasm of farmers' towards adopting technology, provide a practical reference for mitigating the degradation of arable land, and promote the sustainable production of food crops.

\section{Theoretical Framework}

Based on the existing research content and results [32,33,38], the agent of the farmer is divided into four modules: knowledge base, perceptron, communicator, and decisionmaker. The interaction between the modules forms a closed loop, which can directly reflect the state of the agent, as well as the external environment's influence on it and internal feedback. First of all, the knowledge base refers to the agent's cognition, generated by farmers under the continuous updating of internal characteristics and the external environment, so that each farmer's agent is heterogeneous. The internal characteristics of farmers include factors such as individual characteristics of farmers and family resources. The external environment includes policy tools and the influence of mutual information exchange between agents. Secondly, the communicator indicates that the agent of the farmer is interactive, able to receive information about the external environment and, at the same time, display its technology adoption behavior. Thirdly, the perceptron indicates that the agent can perceive changes in the external environment, thereby generating perceptual behaviors and then updating the knowledge base. Finally, the decision-maker is the most important component of the agent and can reflect the decision-making process of farmers based on the BDI structure and generate technology adoption behavior [39-41].

The BDI structure is derived from the work of Bratman, a psychologist [39]. It shows the agent's decision-making process through their beliefs, desires, and intentions. Its advantage lies in its ability to reflect the actual situation. A belief is generated when the agent understands themselves and the environment; a desire is a state that the agent hopes to achieve, but it may not necessarily be achieved; an intention is a goal that the agent most wishes to achieve, a promised "desire", and it influences the agent's behavior [40,41]. The BDI has been applied in the field of land use change research, such as urban development planning simulation, farmer household land-use behavior simulation $[42,43]$, etc. The knowledge base, the communicator, and the perceptron work together as the decision-maker so that farmers' decision-making behavior generates feedback. Specifically, according to the concepts and framework of Peirce, Bromley, and Del Corso from the American School of Institutional Economics [44,45], the formation of a farmer's "belief" depends on receiving external environmental stimuli through the communicator and perceptron, combining these with their knowledge in order to modify the agent's beliefs and form a belief set (B). On this basis, the agent of the farmer filters the belief set to produce a "wish", i.e., the goal that the farmer wishes to achieve the most, and then forms the wish set (D). Based on this, the agent forms an intention set (I), which ultimately affects the behavior of the farmer regarding whether to adopt protective farming techniques.

As an external factor, policy tools will directly act on the agent's perceptions, thereby changing the knowledge base of the farmer. In the context of information-induced policy 
tools, the government provides technical information to farmers through demonstration, publicity, education, etc., which can enhance farmers' technical awareness and farmland protection awareness, and achieve the purpose of promoting technology [23,24]. They can provide farmers with technical information. Regarding subsidized policy tools, these refer to the government's disbursement of capital subsidies to promote the enthusiasm of farmers, such as the "Guiding Opinions on Agricultural Machinery Purchase Subsidies", which can appropriately alleviate the input costs in the farming process $[25,26]$. Farmers enthusiasm towards technology adoption can thus be enhanced. Regulating and restrictive policies can impose fines or ensure accountability among farmers who violate the regulations of environmental quality standards and other policies and regulations to achieve goals, such as the "Implementation Opinions on the Comprehensive Utilization of Crop Straw and Banning Work" [27]; this can enhance farmers' awareness of farming techniques for cultivated land, etc. Therefore, this research hypothesizes that, under the influence of policy tools, farmers are induced to adopt CTT technology, and the impacts vary. On this basis, the theoretical analysis framework shown in Figure 1 is constructed, which presents the cyclic mechanism of mutual influence between the modules of a single agent, and the mechanism of action of external factors on the internal behavior of the agent.

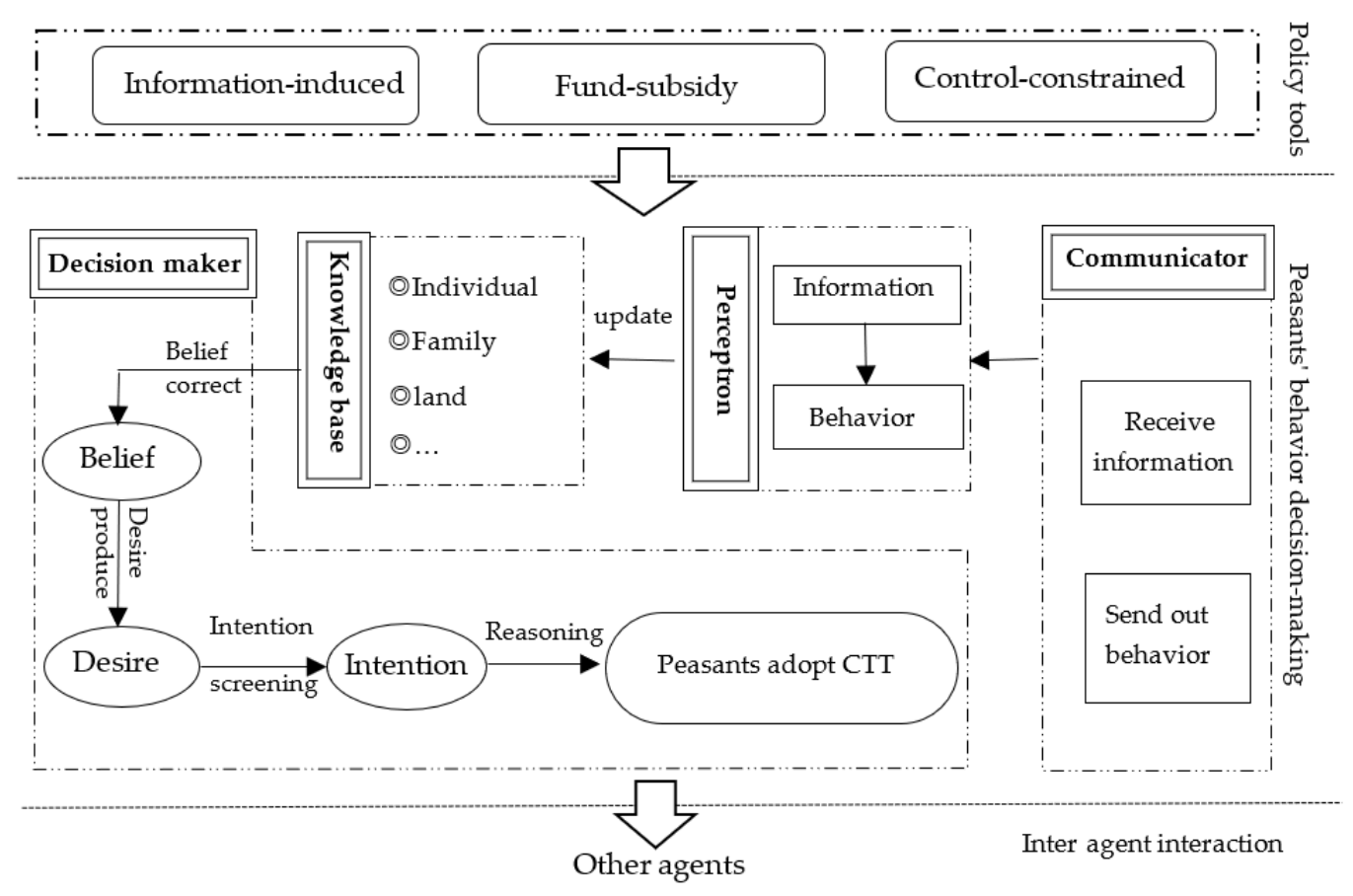

Figure 1. Theoretical framework of farmers' adoption behaviors towards CTT based on Agent BDI structure.

\section{Materials and Methods}

\subsection{Study Areas}

Northeast China is an important corn-producing area, known as one of the three major black soil zones in the world. Liaoning Province is located in the south of Northeast China (see Figure 2), with a total cultivated land area of 4.97 million $\mathrm{hm}^{2}$. Its black soil area accounts for nearly $10.07 \%$ of the total area in Northeast China. It is a largely agricultural province and a major grain production area. However, in recent years, the intensification of the conflict between socio-economic construction and cultivated land protection has introduced a threat to food security [46,47]. Changtu County, Jianping County, and Beipiao City in Liaoning Province were selected as the study areas. Among them, Changtu County is the key protected county with black soil. In 2017, there were 0.82 million farmers, and it has been designated as a pilot area for the extension of CTT. Jianping County contains barren land, with poor climate conditions, serious land desertification, and frequent ten- 
year droughts. In 2017, there were 0.46 million farmers. Beipiao City is located in the transition zone between arid and semi-arid, with a severe lack of water resources. In 2017, there were 0.43 million farmers. There are some problems in this area, such as a shallow farming layer, soil hardening, a decline in organic matter content, and so on [48]. The above areas are suitable for the implementation of CTT. Therefore, exploring farmers' adoption of CTT in this area can not only effectively promote the sustainable development of dry farming agriculture, but also provide a theoretical and empirical reference for other areas.

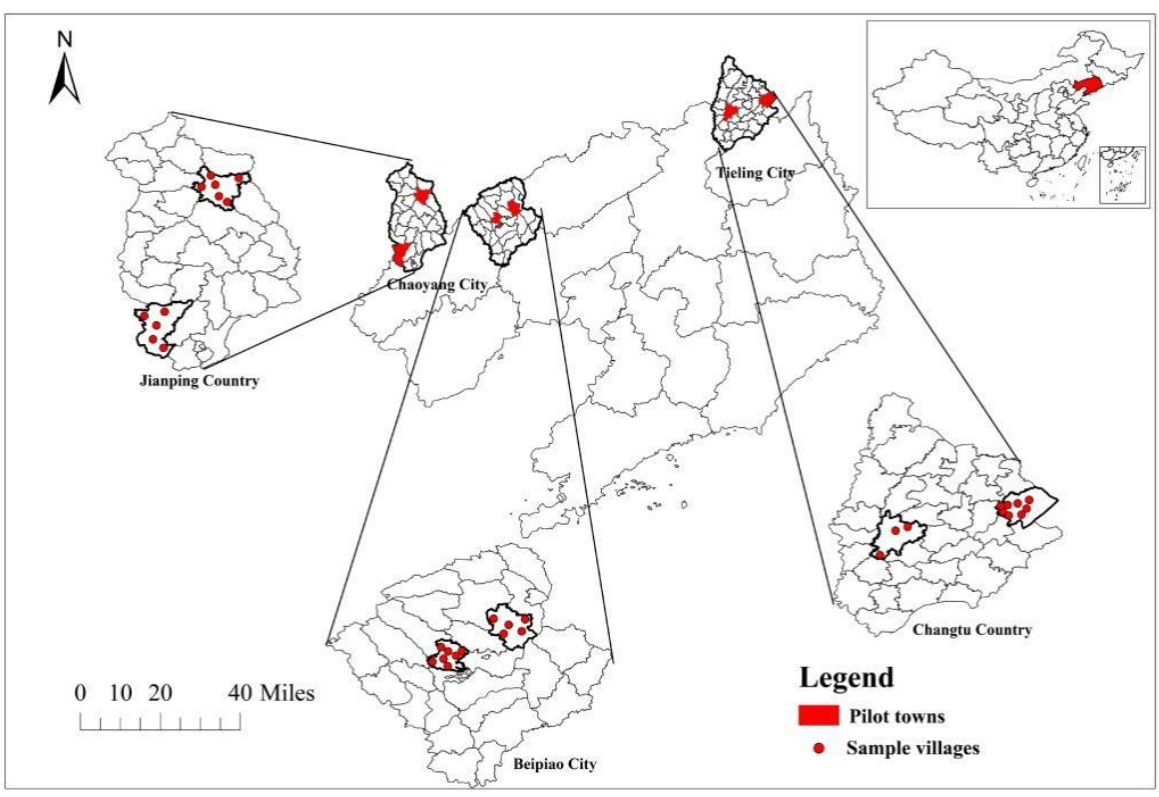

Figure 2. Study area map and spatial distribution of sample villages.

The basic data of this study were derived from a questionnaire survey conducted from July to September 2017. The research group applied the farmer survey to obtain the data. To ensure the reliability of the data, the survey was carried out according to the methods of stratification and random sampling. During the survey process, first, the research team and county-level agricultural and land management personnel jointly analyzed the information of all towns in the selected county in the early stage, including the promotion and application of conservation tillage technology, crop planting patterns, and resources of farmers, etc. Second, the research team classified all towns and villages based on the analyzed information and adopted a stratified sampling method to select 2-3 typical townships in the three survey areas. Several administrative villages, namely Maojiadian Village, Baoli Village, Mayang Village, Shahai Village, Wujianfang Village, and Quanju Village, were selected. A member of the farming community who was familiar with the family situation was randomly selected for interview. The contents of the questionnaire and interview included the basic circumstances of the farmers, family resources, policies, and technology adoption. The research group distributed 380 questionnaires and recovered 364 valid questionnaires, including 113 in Changtu County, 88 in Jianping County, and 163 in Beipiao City, with an effective completion rate of $95.79 \%$. The basic characteristics of the farmers are shown in Table 1. In terms of personal characteristics, the sampled farmers were older, mostly aged 40-60. The educational level of the villagers in the survey area was low, and nearly $90 \%$ of the farmers graduated from primary and secondary school. Village cadres accounted for $17.03 \%$ of the total sample. The attitude towards risk was relatively varied, and there were more peasants with a risk preference, accounting for $45.05 \%$; moreover, $85.44 \%$ of peasants had a herd mentality. In terms of family resources, the average number of laborers in each family was roughly two, and the income of the farmers was mainly derived from agricultural crop planting, accounting for $73.63 \%$. The number of farmland plots is less than 5 , and only $20.33 \%$ of peasants have agricultural 
machinery and facilities; the scale of cultivated land is relatively small, and the sample of less than 3.3 hectares accounts for $78.02 \%$.

Table 1. Basic characteristics of sample (Unit: household, \%).

\begin{tabular}{|c|c|c|c|c|c|c|c|}
\hline Index & Value & Frequency & Proportion & Index & Value & Frequency & Proportion \\
\hline \multirow{5}{*}{ Age } & Under 30 years old & 14 & 3.85 & Proportion of & $<50 \%$ & 268 & 73.63 \\
\hline & $30-40$ years old & 52 & 14.29 & agricultural income & $>=50 \%$ & 96 & 26.37 \\
\hline & $41-50$ years old & 142 & 39.01 & \multirow{5}{*}{$\begin{array}{l}\text { Net agricultural } \\
\text { population }\end{array}$} & 0-1 people & 127 & 34.89 \\
\hline & 51-60 years old & 104 & 28.57 & & 2-3 people & 224 & 61.54 \\
\hline & Over 60 years old & 52 & 14.28 & & 4 people & 13 & 3.57 \\
\hline \multirow{4}{*}{ Education } & Primary school & 86 & 23.63 & & $<=5$ pieces & 248 & 68.13 \\
\hline & Junior middle school & 249 & 68.41 & & 5-10 pieces & 98 & 26.92 \\
\hline & $\begin{array}{l}\text { High school } \\
\text { and above }\end{array}$ & 29 & 7.96 & \multirow[t]{2}{*}{$\begin{array}{l}\text { Fineness degree of } \\
\text { cultivated land }\end{array}$} & 10-15 pieces & 16 & 4.39 \\
\hline & Risk preference & 164 & 45.05 & & 15-20 pieces & 1 & 0.28 \\
\hline \multirow[t]{2}{*}{ Risk attitude } & Risk neutral & 90 & 24.73 & \multirow{4}{*}{$\begin{array}{c}\text { Ownership of } \\
\text { agricultural } \\
\text { machinery }\end{array}$} & $>20$ pieces & 1 & 0.28 \\
\hline & Risk aversion & 110 & 30.22 & & yes & 74 & 20.33 \\
\hline \multirow{2}{*}{ Social stratum } & Village cadres & 62 & 17.03 & & no & 290 & 79.67 \\
\hline & Non-village cadres & 302 & 82.97 & & $<3.3$ hectares & 284 & 78.02 \\
\hline \multirow{2}{*}{$\begin{array}{c}\text { Group } \\
\text { psychology }\end{array}$} & yes & 311 & 85.44 & \multirow{2}{*}{ Cultivated land scale } & $\begin{array}{c}3.3-6.7 \\
\text { hectares }\end{array}$ & 43 & 11.81 \\
\hline & no & 53 & 14.56 & & $>6.7$ hectares & 37 & 10.17 \\
\hline
\end{tabular}

\subsection{Research Method}

\subsubsection{Modeling Process}

The basic component of the agent model is the "agent". The agent usually has the four basic attributes of autonomy, reactivity, initiative, and interactivity. It can autonomously control its behavior and internal state, interact with other agents through communication language, and perceive external environmental stimuli to "display" complex behaviors such as learning, adaptation, etc. [34]. Compared with other models, the agent model can flexibly describe the evolution of complex spatial systems "from bottom to top" in a visual manner, portray the dynamic behaviors of interactive activities between farmers in the complex system, and form an interactive "agent-environment" relationship within the system, in order to explore in depth its influence mechanism and, finally, the global behavior that emerges in a nonlinear manner according to their respective behavior rules [32-34]. Recently, the application of the agent model to study farmers' behaviors has become a research trend [35,36]. In this study, Netlogo6.2.0 simulation software was selected to build the simulation model of farmers' adoption of conservation tillage technology. The software includes three parts: the user operation page, the model information page, and the routine writing page $[49,50]$. The software has three types of agents. Firstly, turtles are agents that can move within the simulation space according to instructions. In this study, turtles refer to farmers. Secondly, tiles refer to the virtual world, i.e., the production and living area of farmers. Thirdly, links are the connections between agents, i.e., the interactive connections between farmers. The operation of the model is realized through a combination of program settings and tools (buttons and sliders). The running time and speed of the model can be controlled by the modeler. The simulation results can be observed via a monitor, or a drawing curve can be generated using the software. Compared with other simulation software, this program has the advantages of simple syntax, complete functions, and wide coverage. It can reflect people in the real world on the network, and the agent can evolve according to the behavior rules specified by the modeler. It is suitable for research on farmers' behavior. Moreover, the software has been widely used in fields related to land use change, such as the evolution of farmers' behavior [51-53].

Based on the above analysis and existing research results [50-52], the simulation model process was designed with six stages, as shown in Figure 3. Firstly, the objective of the simulation was to explore the evolution of farmers' adoption behavior towards CTT under the influence of policy tools. Secondly, we sought to determine the agent attribute: in the initial stage, the main task was to create heterogeneous agents, including the number 
of agents, agent type, the initial attributes of the agent (belief, desire, and intention), and an association between principles. To ensure that the model was consistent with the actual situation, the main body of farmers was determined based on the data collected from the farmer survey and statistical yearbook data relating to Liaoning Province. Thirdly, we wished to establish the agent model by applying the Netlogo simulation platform, importing the agent attributes and assigning values based on the simulation objectives, and building a complex network of the agent representing the farmer, including basic attributes such as agent distribution, communication, color, shape, and so on. Fourthly, we conducted agent behavior refinement, including the setting of agent decision-making behavior rules to study the farmers' decision-making process and their behavior change rules based on the BDI structure, in order to evaluate their behavior evolution; we also performed the design of policy tools, wherein, according to the existing policies, three types of policy tools were set up, namely the realization scenarios of information guidance, capital subsidy, and regulatory constraints in the model. Fifthly, we conducted the simulation operation: the simulation model could be directly realized on the computer through routine writing. With time, the changes in agent attributes and the interactive relationship between agents will be intuitively presented in the system. Finally, we generated simulation results. The Netlogo simulation platform has three modules: control, input, and output. The simulation results can be exported through the software's drawing function to demonstrate the agent's evolution.

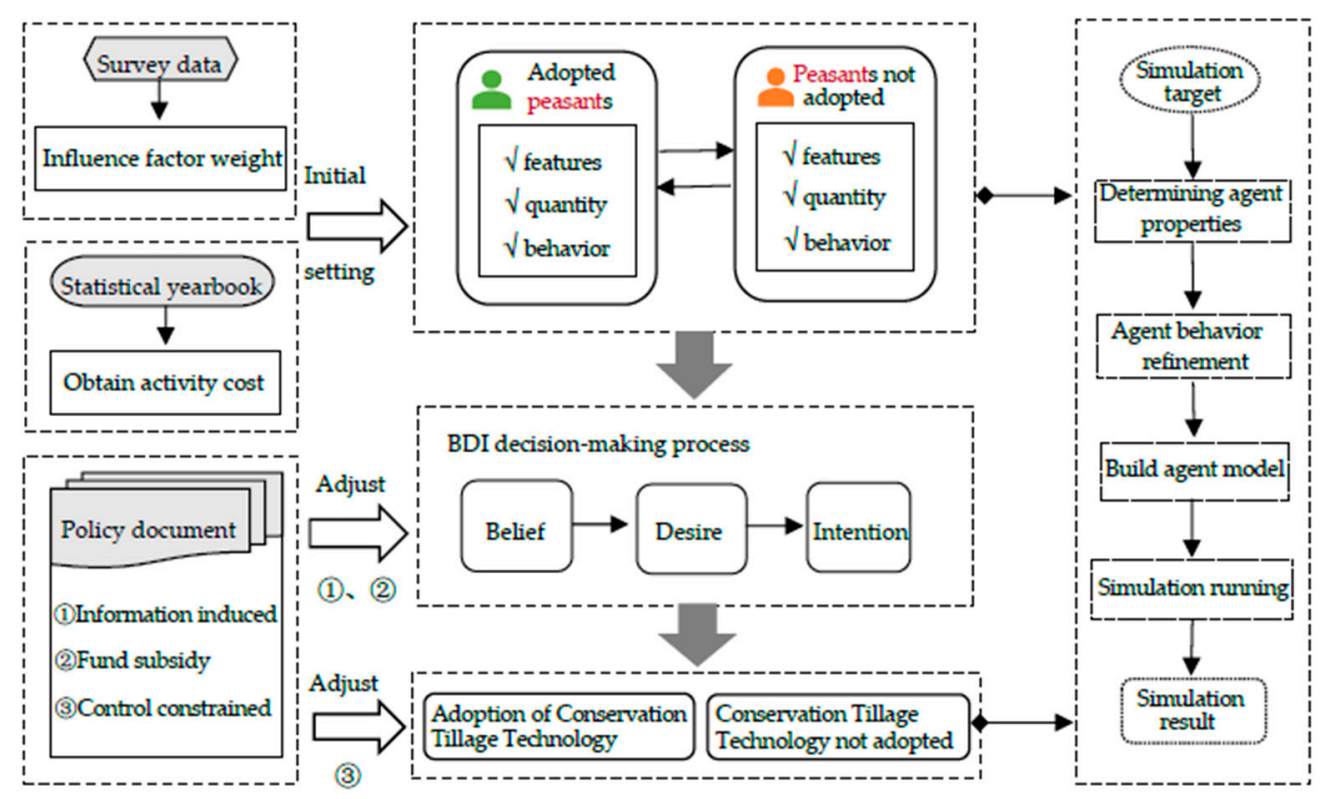

Figure 3. Simulation process for peasants' adoption behaviors towards CTT.

\subsubsection{Agent Attributes}

The establishment of the agent model emphasizes the behavior rules of the agent. Based on the above analysis, considering the reliability, effectiveness, and stability of the model, combined with the existing research and data acquisition, the agent attributes of farmers were set [32-36]. It is known that, in the process of selecting farming technology, farmers mainly face two choices: using the current farming technology and adopting new farming technology. The classification tree method can be used to roughly divide the main body into three categories based on two criteria (whether to adopt straw mulching technology and straw burning): set $\mathrm{P}=\left\{{ }^{\prime \prime} \mathrm{P}_{1}{ }^{\prime},{ }^{\prime} \mathrm{P}_{2}{ }^{\prime},{ }^{\prime}{ }^{\prime} \mathrm{P}_{3}\right.$ " $\}$ (see Figure 4). " $\mathrm{P}_{1}$ " reflects farmers who adopt straw mulching technology, " $\mathrm{P}_{2}$ " refers to those who adopt straw burning, and " $\mathrm{P}_{3}$ " refers to farmers who use other straw utilization methods. In accordance with the survey data, 364 agents were created in the model. In addition, considering the contingency and reality of farmers' communication, the composition of the farmers' social 
network and technology adoption were obtained according to the survey. Each agent was randomly assigned 1-5 agents with close contact, and the type was not limited. At this point, there were 137 " $\mathrm{P}_{1}$ " farmers, accounting for $37.64 \%$ of the total sample; there were 65 farmers in the " $\mathrm{P}_{2}$ " category, accounting for $17.86 \%$ of the total sample; and there were $162 " \mathrm{P}_{3}$ " farmers, accounting for $44.50 \%$ of the total sample.

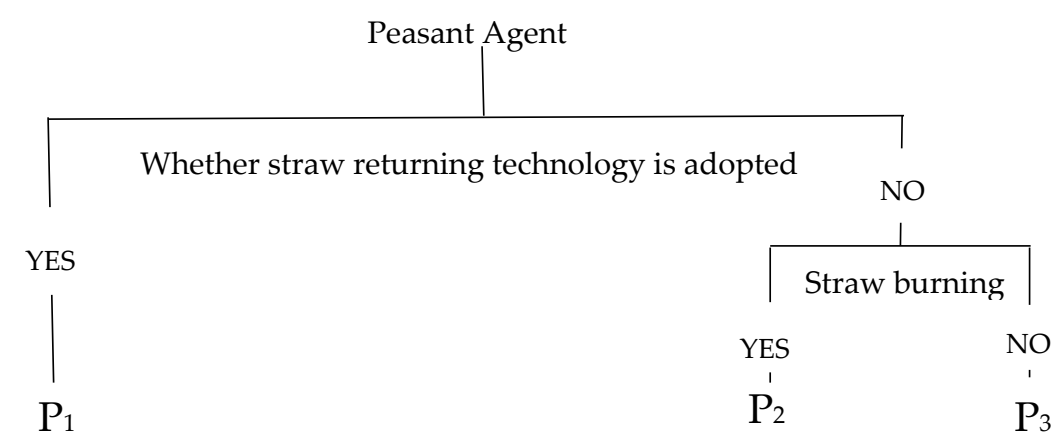

Figure 4. Classification of farmers.

\subsubsection{Agent Behavior Decision}

Based on the above theoretical analysis and framework construction, this research adopted the BDI structure to describe and interpret the decision-making process involved in farmers' adoption of CTT. This included three stages. The first was the belief stage. This refers to the generation of a certain set of beliefs under the influence of the farmers' characteristics and the perception of the external environment. The second was the desire stage: farmers will generate multiple sets of desires based on their farming goals (when they have their own beliefs) and the choice of farming technology. The third stage involved determining the intention: under the established beliefs, through the screening of the set of desires, the intention of the farmers is finally determined. This has a direct effect on their technology adoption behavior. The following paragraphs describe the specific process of farmers' decision-making behavior.

Belief (B)

Belief refers to the viewpoint or cognition held by the agent through the combination of their perceptions of the external environment and its characteristics, and the belief set is formed by updating the belief function under the constantly updated perception of the external environment [39-41]. In the process of technology adoption, the external environment perceived by farmers includes social networks, policy tools, and various means by which farmers obtain agricultural technology information; the formation of farmers' features includes their characteristics and family resources, such as age, farming population, degree of cultivated land fragmentation, and other factors [18-20]. The farmers' belief function is constructed as follows:

$$
\begin{gathered}
\mathrm{B}_{\mathrm{T}}=\left\{\mathrm{P}_{\mathrm{T}}, \mathrm{E}_{\mathrm{T}}\right\} \\
\mathrm{P}_{\mathrm{T}}=\sum_{\mathrm{i}=1}^{\mathrm{n}} \mathrm{s}_{\mathrm{i}} \times \mathrm{P}_{\mathrm{Ti}} \\
\mathrm{E}_{\mathrm{T}}=\sum_{\mathrm{i}=1}^{\mathrm{n}} \mathrm{s}_{\mathrm{i}} \times \mathrm{E}_{\mathrm{Ti}}+\mathrm{q}_{2}
\end{gathered}
$$

In Formula (1), $\mathrm{B}_{\mathrm{T}}$ is the belief of farmers at time $\mathrm{t}$; $\mathrm{P}_{\mathrm{T}}$ represents the characteristics of farmers at time $t ; E_{t}$ is the external environment perceived by farmers at time $t . \mathrm{P}_{\mathrm{Ti}}$ is the influencing factor of farmers characteristics; $\mathrm{E}_{\mathrm{Ti}}$ represents the $\mathrm{i}_{\text {th }}$ external environmental factor; and $\mathrm{q}_{1}$ and $\mathrm{q}_{2}$ are error terms. In Formulas (2) and (3), $\mathrm{S}_{\mathrm{i}}$ represents the weight of the $i_{\text {th }}$ influence factor. According to the above analysis, Table 2 shows the definition and 
description of the influencing factors. The adoption of straw returning technology was set as the dependent variable. If adopted, the value is 1 , and if not, it is 0 . Age, educational background, social class, risk attitude, number of farmers, fragmentation of cultivated land, ownership of agricultural machinery and tools, the proportion of agricultural income, awareness of environmental protection, and benefit cognition were set as independent variables to adjust "belief". According to the setting of relevant research variables, the value was assigned based on a 5-level Likert scale and actual data.

Table 2. Variable description and statistical analysis.

\begin{tabular}{|c|c|c|c|c|c|}
\hline Name & Assignment Description & Mean & $\begin{array}{c}\text { Standard } \\
\text { Deviation }\end{array}$ & Minimum & Maximum \\
\hline Adopted or not & $\begin{array}{l}\text { Whether straw mulching technology is adopted? } \\
\qquad 1=\text { yes; } 0=\text { no }\end{array}$ & 0.376 & 0.485 & 0 & 1 \\
\hline Age & $\begin{array}{l}\text { What is your age? } 1=<30 ; 2=30 \sim 40 ; 3=41 \sim 50 ; \\
\qquad \begin{array}{c}4=51 \sim 60 ; 5=>60 \text { years old. } \\
\text { What is your educational background? }\end{array}\end{array}$ & 3.352 & 1.016 & 1 & 5 \\
\hline Education & $\begin{array}{c}1=\text { primary school and below } ; 2=\text { junior high } \\
\text { school; } 3=\text { high school and above. }\end{array}$ & 1.843 & 0.54 & 1 & 3 \\
\hline Social stratum & Are you a village cadre? 1 = yes; $0=$ no. & 0.17 & 0.376 & 0 & 1 \\
\hline Risk attitude & 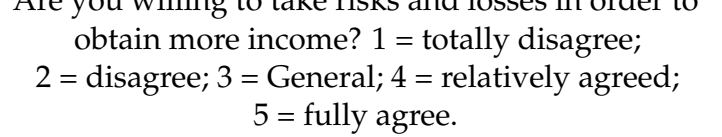 & 3.206 & 1.049 & 1 & 5 \\
\hline Number of farmers & $\begin{array}{c}\text { What is the number of pure business farmers in } \\
\text { your family? The value is } 0-4 \text { persons. }\end{array}$ & 1.712 & 0.807 & 0 & 4 \\
\hline $\begin{array}{l}\text { Farmland } \\
\text { fragmentation }\end{array}$ & $\begin{array}{l}\text { What is the number of cultivated land plots in } \\
\text { your family? } 1=<5 ; 2=5 \sim 10 ; 3=10 \sim 15 ; 4=15 \sim 20 \\
\qquad 5=>20 \text { pieces. }\end{array}$ & 1.372 & 0.606 & 1 & 5 \\
\hline $\begin{array}{l}\text { Agricultural } \\
\text { machinery }\end{array}$ & $\begin{array}{l}\text { Does your family have agricultural machinery } \\
\text { facilities? } 1=\text { yes; } 0=\text { no. }\end{array}$ & 0.203 & 0.403 & 0 & 1 \\
\hline $\begin{array}{l}\text { Proportion of } \\
\text { agricultural } \\
\text { income }\end{array}$ & $\begin{array}{l}\text { What is the proportion of your family's } \\
\text { agricultural income? } 1=0-20 \% ; 2=20-40 \% \text {; } \\
3=40-60 \% ; 4=60-80 \% ; 5=80 \sim 100 \% \text {. }\end{array}$ & 3.728 & 1.068 & 1 & 5 \\
\hline $\begin{array}{l}\text { Environmental } \\
\text { awareness }\end{array}$ & $\begin{array}{l}\text { Do you think straw mulching can protect the } \\
\text { environment? } 1=\text { totally disagree; } 2 \text { = disagree; } \\
3=\text { General; } 4=\text { relatively agreed; } 5=\text { fully agree. }\end{array}$ & 3.887 & 0.945 & 1 & 5 \\
\hline Benefit cognition & $\begin{array}{c}\text { Do you think straw mulching technology can } \\
\text { improve crop yield? } 1=\text { totally disagree, } 2=\text { not } \\
\text { quite agree, } 3=\text { average, } 4=\text { relatively agree, } \\
5=\text { totally agree. }\end{array}$ & 3.967 & 1.033 & 1 & 5 \\
\hline
\end{tabular}

Desire (D)

Desire is combined with a belief in the state that the agent wishes to achieve or maintain, and it is the initial motivation behind the agent's behavior. Generally, the agent's wish is an expectation and judgment based on the current environment and state. The agent can have multiple wishes, but not all of them will be realized [39-41]. When faced with the choice of farming technology, on the one hand, as social citizens, driven by policy constraints and a sense of social responsibility, farmers have a spiritual desire to protect the natural environment. On the other hand, as "rational, economic individuals", farmers have a real desire to obtain the maximum income. However, due to the income from straw treatment, this is not only reflected in the increase in capital income, but also in the relatively long income period $[7,54,55]$. Therefore, this study only considered farmers' activity-based costs under different straw treatment methods. Based on this, the farmers' desire function is constructed as follows:

$$
\mathrm{D}_{\mathrm{T}}=\left\{\mathrm{B}_{\mathrm{T}}, \mathrm{C}_{\alpha}\right\}
$$




$$
\mathrm{C}_{\alpha}=\frac{\mathrm{c}_{\alpha}}{364} \sum_{\mathrm{m}=1}^{\mathrm{m}=364} \mathrm{C}_{\mathrm{m}}
$$

In Equation (5), $\mathrm{D}_{\mathrm{T}}$ represents the desire of farmers at time $\mathrm{T} ; \mathrm{C}_{\alpha}$ is the relative cost of straw treatment, i.e., the ratio of the activity cost of straw treatment per hectare to the overall average cost, $\alpha$. The values are 1,2, and 3, which, respectively, represent the relative costs of different straw treatment methods, i.e., straw mulching, straw incineration, and others. $c_{\alpha}$ is the cost of straw treatment for farmers; $C_{m}$ is the total cost of straw treatment for all samples; $m$ is the total number of farmers, and the values are $1,2,3, \ldots, 364$.

Intention (I)

The intention is the agent's action trend and the key to whether the agent can take action. Desire is the basis of intention, but intention is more specific than desire [37-41]. For example, farmers who adopt straw mulching are more willing to seek information about agricultural technology, and their initial intention value is greater. With the evolution of the model, their intention was found to be more inclined towards maintaining the status quo. For farmers who do not adopt straw returning, their initial intention value is small, but their intention changes significantly during the evolution of the model. Generally, farmers' decision-making intention is a function expressed comprehensively by belief and desire, and its expression is:

$$
\mathrm{I}_{\mathrm{T}_{\beta}}=\left\{\mathrm{B}_{\mathrm{T}}, \mathrm{D}_{\mathrm{T}}\right\}
$$

where $\mathrm{I}_{\mathrm{T}_{\beta}}$ is the farmer's intention at time $\mathrm{T}$, and the farmer's behavior is determined by its intended value. The greater the intention value, the stronger the farmer's intention. Therefore, according to the characteristics of heterogeneous farmers, the behavior decisionmaking rules of $P_{1}, P_{2}$, and $P_{3}$ agents are set as shown in the Table 3 . Specifically, farmers decision-making can be divided into three categories according to the change in their intention value: if the current intention value is greater than the previous period, the main body's willingness to adopt conservation tillage technology is enhanced, and it is easy to make random changes to the farming technology. If the current intention value is equal to the previous period, this indicates that the agent's intention to adopt technology has not changed significantly. At this time, the technology will be selected according to the adoption behavior of relatives and friends. If the current intention value is less than the previous stage, farmers' willingness to adopt technology will weaken, and the farming technology is unlikely to change easily.

\begin{tabular}{|c|c|c|c|}
\hline Intention & Decision & Characteristics & Behavior Description \\
\hline $\mathrm{I}_{\mathrm{T}}<\mathrm{I}_{\mathrm{T}+1}$ & $\begin{array}{l}\text { Random } \\
\text { selection }\end{array}$ & $\begin{array}{l}\text { It is easy to make random } \\
\text { changes to farming } \\
\text { techniques. }\end{array}$ & $\begin{array}{l}\mathrm{P}_{1} \text { : Maintain the status quo. } \\
\mathrm{P}_{2} \text { : Farmers randomly transformed into " } \mathrm{P}_{1} \text { " or " } \mathrm{P}_{3} \text { " type. } \\
\mathrm{P}_{3} \text { : Randomly transformed into " } \mathrm{P}_{1} \text { " type farmers. }\end{array}$ \\
\hline $\mathrm{I}_{\mathrm{T}}=\mathrm{I}_{\mathrm{T}+1}$ & $\begin{array}{l}\text { Emulate } \\
\text { relatives and } \\
\text { friends }\end{array}$ & $\begin{array}{l}\text { Easily influenced by } \\
\text { social networks to make } \\
\text { changes. }\end{array}$ & $\begin{array}{l}\mathrm{P}_{1} \text { : If more than half of the " } \mathrm{P}_{2} \text { " and " } \mathrm{P}_{3} \text { " farmer are present, they will be } \\
\text { randomly transformed into " } \mathrm{P}_{2} \text { " or " } \mathrm{P}_{3} \text { " farmers. } \\
\mathrm{P}_{2} \text { : If more than half of the surrounding " } \mathrm{P}_{1} \text { " and " } \mathrm{P}_{3} \text { " farmers are randomly } \\
\text { transformed into " } \mathrm{P}_{1} \text { " or " } \mathrm{P}_{3} \text { " farmers. } \\
\mathrm{P}_{3} \text { : If more than half of the " } \mathrm{P}_{1} \text { " type farmers are present, they will be randomly } \\
\text { transformed into " } \mathrm{P}_{1} \text { " type farmers; If more than half of the " } \mathrm{P}_{2} \text { " type farmers are } \\
\text { around, they will be randomly transformed into " } \mathrm{P}_{2} \text { " type farmers. }\end{array}$ \\
\hline $\mathrm{I}_{\mathrm{T}}>\mathrm{I}_{\mathrm{T}+1}$ & $\begin{array}{l}\text { Choose } \\
\text { carefully }\end{array}$ & $\begin{array}{l}\text { It is not easy to change } \\
\text { the choice of farming } \\
\text { technology. }\end{array}$ & $\begin{array}{l}\mathrm{P}_{1} \text { : If the intention value is greater than the average value of " } \mathrm{P}_{1} \text { ", follow the } \\
\text { example of relatives and friends; on the contrary, maintain the status quo. } \\
\mathrm{P}_{2} \text { : If the intended value is greater than the average value of " } \mathrm{P}_{2} \text { ", follow the } \\
\text { example of relatives and friends; on the contrary, maintain the status quo. } \\
\mathrm{P}_{3} \text { : If the intended value is greater than the average value of " } \mathrm{P}_{3} \text { ", follow the } \\
\text { example of relatives and friends; on the contrary, maintain the status quo. }\end{array}$ \\
\hline
\end{tabular}

Table 3. Agent behavior decision rule description. 


\subsubsection{Policy Tool Simulation Scenarios}

To achieve the research purpose, referring to the existing research simulation scenario design [49-51], we controlled each group of experiments within 20 cycles. As each cycle corresponded to one year, we were able to imitate the evolution of farmers' adoption behavior regarding conservation tillage technology over the next 20 years. At the same time, in order to reduce random errors in the simulation process, the three types of policy tools were designed to run 50 times at each implementation intensity; finally, the effective data average of the successful runs was calculated as the final simulation result. To observe the dynamic changes in farmers' behavior under the implementation of information guidance, fund subsidy, and regulation constraint policy tools, it is necessary to introduce the implementation intensity in order to quantify the policy, i.e., the policy intensity referred to in this study is the implementation intensity of government policy, which is unrelated to its effect.

Scenario 1: The "information-induced" policy tool, as an external environmental factor, can change farmers' technical cognition and information acquisition $[25,26]$. Based on this, the implementation of an information-induced policy can be used as an external factor to change farmers' beliefs and intentions and ultimately affect the main decisionmaking behavior. The updated belief function is:

$$
\mathrm{FB}_{\mathrm{t}+1}=\left(1+\mu_{\mathrm{i}}\right) \mathrm{B}_{\mathrm{t}}
$$

where $B_{t+1}$ is the farmer's belief at time $t+1$, and $B_{t}$ is the farmer's belief at time $t ; \mu_{1}$ is the implementation intensity of the information-induced policy. The change step of policy intensity in the simulation scenario is $0.1 ; \mu_{1}=0$ is the initial scenario without the effect of the policy; when $\mu_{\mathrm{i}}=1$, the policy implementation is the strongest, and $\mu_{\mathrm{i}}=\{0,0.1, \ldots, 1\}$.

Scenario 2: The "fund-subsidy" policy tools generally include tax preferential policies, agricultural machinery subsidy policies, etc. [27,28]. To reduce farmers' operating costs and encourage them to adopt CTT, at the same time, the implementation of the policy is accompanied by the improvement of farmers' technical cognition. Therefore, the design of the simulation scenario will ultimately affect farmers' decision-making by changing their beliefs and aspirations. Its function is updated to:

$$
\begin{aligned}
\mathrm{FB}_{\mathrm{t}+1} & =\left(1+\mu_{2}\right) \mathrm{B}_{\mathrm{t}} \\
\mathrm{FC}_{\mathrm{t}+1} & =\left(1-\mu_{2}\right) \mathrm{C}_{\mathrm{t}}
\end{aligned}
$$

where $B_{t+1}$ and $B_{T}$ are farmers' beliefs at $t+1$ and $t$, respectively; $C_{t+1}$ is farmers' straw treatment cost at $t+1$, and $C_{t}$ is farmers' straw treatment cost at $t$. $\mu_{2}$ is the implementation intensity of the fund-subsidy policy, and the value is $\{0,0.1, \ldots, 1\}$. The value changes from small to large, i.e., the implementation intensity of the policy changes from weak to strong.

Scenario 3: A "control-constrained" policy tool generally provides administrative instructions, such as incineration standards, and implementation methods include warnings, fines, etc. [21,54]. It plays a warning role for ordinary farmers, while it is implemented for farmers who use straw burning, which increases the farmers' operating costs and improves their awareness of cultivated land protection. Based on this, the design of the simulation scenario can change farmers' beliefs and wishes, and the function is updated as follows:

$$
\begin{aligned}
& \mathrm{FB}_{\mathrm{t}+1}=\left(1+\mu_{3}\right) \mathrm{B}_{\mathrm{t}} \\
& \mathrm{FC}_{\mathrm{t}+1}=\left(1+\mu_{3}\right) \mathrm{C}_{\mathrm{t}}
\end{aligned}
$$

where $B_{t+1}$ is the farmer's belief at time $t+1 ; B_{T}$ is the farmer's belief at time $t ; C_{T+1}$ is the farmer's straw treatment cost at time $t+1 ; C_{t}$ is the farmer's straw treatment cost at time $\mathrm{t} ; \mu_{3}$ is the policy punishment intensity, and the value is $\{0,0.1, \ldots, 1\}$. It is worth noting that, due to the differences in the main types of farmers, the policy is implemented for $\mathrm{P}_{2}$ 
farmers, i.e., farmers' beliefs and wishes are affected. For $\mathrm{P}_{1}$ and $\mathrm{P}_{3}$ farmers, only their beliefs change, and this ultimately changes the farmers' intentions.

\section{Results}

\subsection{Model Checking}

Based on the Agent model as a forecasting tool for real scenes, the validity, reliability, and stability of the model needed to be tested. Therefore, we further tested the consistency between the model prediction results and the actual survey results in a statistical sense, using SPSS20.0 statistical analysis tools, and using a hierarchical chi-square test method to test the results of the policy tool stimuli in the two groups. It should be noted that, due to the limitations of field surveys, this process only involved a period of result verification. In addition, the implementation intensity of the subsidy policy could be directly quantified through field surveys. The implementation intensity of the subsidy policy in the survey area was approximately 0.3 , so only the results of such policy tools at an intensity of 0.3 were tested. The results showed that the "Breslow-Day Tarone's" value was 0.732 , the "Cochran's" value was 0.528 , the "Mantel-Haenszel" value was 0.829 , and the significance test size of each index was greater than 0.05 . These values indicate that the actual results and the predicted results were not statistically different from each other, i.e., it passes the inspection.

\subsection{Farmers' Decision Parameters}

Based on the above-mentioned model construction, in this study, we standardized the survey data in advance, i.e., the dependent variables and independent variables of the survey data were standardized to eliminate the influence of differences in dimensions and quantities, so that different variables were comparable. Then, SPSS20.0 software was used for multiplexing. Linear regression was used to obtain standardized regression coefficients, i.e., the impact factor coefficients. Normally, the factor coefficient is between -1 and 1 . By comparing the absolute value of the coefficient, the influence of each factor is determined. The larger the absolute value, the greater the influence. To simplify the model, the importance of the research setting factors could be determined by the weight of the coefficient; the standard regression coefficient of a factor is the proportion of the total standard regression coefficient, and the value range is set to a total value of 1 . As shown in the following Table 4, the regression results indicated that social class, agricultural machinery, environmental awareness, and benefit perception all passed the $1 \%$ level of significance positive test. Farmers' age and cultivated land characteristics had a $5 \%$ level of significant positive impact. Risk attitude was significant at the $10 \%$ level. The educational background, the number of farmers, and the proportion of agricultural income failed the test, so they were removed from the model construction. In addition, according to the multicollinearity of the VIF detection variables, the maximum value of VIF was 2.384, which was less than 10, indicating that there was no collinearity problem.

Farmers' willingness is determined by their beliefs and operating costs. According to the National Agricultural Product Cost and Benefit Collection (2018), the total cost of corn crops in Liaoning Province was 13,659.60 yuan/ha, including production costs of 10,102.80 yuan/ha and land costs of 3556.80 yuan/ha. To reflect the differences in the operating costs of different farmers, three types of relative production costs were introduced. For such farmers, in addition to the basic production cost, an additional fee for the straw shredder is required. Without considering multiple cropping, according to the market price of agricultural machinery and the "Liaoning Provincial Statistical Yearbook (2018)", the cost of the straw shredder is generally around 600 yuan/ha. At the same time, straw mulching on the field can reduce the use of chemical fertilizers. Referring to the existing research on the cost of straw treatment $[7,52,53]$, it is known that the cost of compound fertilizer per hectare can be reduced by straw mulching on the field by around 30 yuan/ha. For similar farmers, in addition to paying the basic production costs, straw burning can effectively kill insects and sterilize the field under a high-temperature environment, thereby reducing 
pesticide use costs by 215.55 yuan/ha. For $P_{3}$ farmers, the costs and cost savings of these treatment methods are difficult to calculate, so we have not considered them here. As the desire function is determined by the relative cost, the total average cost of the research setting was set to 1 , and the relative cost of each straw treatment method was calculated, as shown in Table 5.

Table 4. Regression results and model settings.

\begin{tabular}{|c|c|c|c|c|c|c|}
\hline \multirow{2}{*}{ Variable } & \multicolumn{2}{|c|}{ Non-standardized Coefficient } & \multirow{2}{*}{$\begin{array}{c}\text { Standardization Factor } \\
\text { Beta }\end{array}$} & \multirow{2}{*}{ Significance } & \multicolumn{2}{|c|}{ Model Setting } \\
\hline & Coefficient & Standard Error & & & Result & Weight \\
\hline Age & 0.044 & 0.020 & 0.093 & 0.028 & Keep & 0.076 \\
\hline Risk attitude & 0.038 & 0.019 & 0.083 & 0.051 & Keep & 0.068 \\
\hline $\begin{array}{l}\text { Cultivated land } \\
\text { fragmentation }\end{array}$ & 0.065 & 0.028 & 0.100 & 0.020 & Keep & 0.082 \\
\hline Social class & 0.282 & 0.051 & 0.233 & 0.000 & Keep & 0.190 \\
\hline Agricultural machinery & 0.241 & 0.049 & 0.208 & 0.000 & Keep & 0.170 \\
\hline Benefit perception & 0.089 & 0.021 & 0.189 & 0.000 & Keep & 0.154 \\
\hline Environmental awareness & 0.163 & 0.023 & 0.318 & 0.000 & Keep & 0.260 \\
\hline Education & -0.021 & -0.04 & -0.024 & 0.582 & Remove & 0.000 \\
\hline Number of farmers & 0.023 & 0.025 & 0.039 & 0.347 & Remove & 0.000 \\
\hline $\begin{array}{l}\text { Proportion of } \\
\text { agricultural income }\end{array}$ & 0.024 & 0.019 & 0.053 & 0.216 & Remove & 0.000 \\
\hline Constant & -1.266 & 0.167 & - & - & - & - \\
\hline
\end{tabular}

Table 5. Costs of straw treatment methods for farmers.

\begin{tabular}{|c|c|c|c|c|c|c|}
\hline \multirow{2}{*}{ Type } & \multicolumn{2}{|c|}{ Basic Cost } & \multicolumn{2}{|c|}{ Cost Saving } & \multirow{2}{*}{$\begin{array}{c}\text { Total Cost } \\
\text { Yuan/ha }\end{array}$} & \multirow{2}{*}{ Relative Cost } \\
\hline & Cost Structure & Yuan/ha & Cost Structure & Yuan/ha & & \\
\hline Returning straw to the field $\left(\mathrm{P}_{1}\right)$ & $\begin{array}{l}\text { Production cost } \\
+ \text { crusher cost }\end{array}$ & $10,162.80$ & $\begin{array}{l}\text { Compound } \\
\text { fertilizer cost }\end{array}$ & 450.00 & 9712.80 & 1.013 \\
\hline Straw burning $\left(\mathrm{P}_{2}\right)$ & Production cost & 9562.80 & Pesticide cost & 14.37 & 9347.25 & 0.981 \\
\hline Other types $\left(\mathrm{P}_{3}\right)$ & Production cost & 9562.80 & - & - & 9562.80 & 0.997 \\
\hline \multicolumn{5}{|c|}{ Total cost average } & 9591.3 & 1.000 \\
\hline
\end{tabular}

From the above analysis, it can be seen that the initial intention value was calculated according to the belief and desire in order to quantify the decision-making behavior of farmers. For farmers who adopted the straw mulching technique, the initial intention value was the highest, with an average of 2.697. For $\mathrm{P}_{2}$ farmers, their initial intention value was the lowest, with an average of 1.840. For $\mathrm{P}_{3}$ farmers, the average intention value was 2.379. Farmers' decision-making behaviors are a process in which the subject's perception of the internal and external environments is transformed into internal cognition. Consequently, different types of farmers have significant differences in environmental awareness and technological cognition, as well as their ability to learn and accept new technologies in the initial period. In addition, the main agricultural operation process of farmers is different from the constraints of cost, individual cognition, and resources. This result is consistent with modeling expectations.

\subsection{Farmers' Decision-Making Behavior under Information-Induced Policy}

To explore the impact of policy on farmers' technology adoption behavior, the main behavior was observed from "horizontal" and "vertical" perspectives. Horizontal observation refers to the change in farmers' main behaviors over time under the same policy intensity; vertical observation refers to the change in peasants' behavior with policy intensity in the same period. The following Figure 5 shows that the implementation intensity of the information-induced policy is $\mu_{1}=1.0$, reflecting the horizontal change process for the agent's decision-making behavior. On the whole, the curve of farmers' adoption of conservation tillage technology shows a changing trend of first increasing, then decreasing, 
and then becoming stable. In 1-3 cycles, the number of farmers adopting CTT increased steadily, overlapping with the "not adopted" trend line for the first time. In the third cycle, an "inflection point" appeared on the trend line. At this time, the number of agents adopting CTT reached the maximum, nearly 195 , accounting for $53.57 \%$ of the total sample. Then, during the third to sixth weeks of the simulation operation, the number of agents adopting CTT decreased steadily. During this period, the number of two types of agents overlapped for the second time, and, finally, the curve tended to flatten after the seventh year. At this time, the number of agents adopting the technology was nearly 176, accounting for $48.35 \%$ of the total sample.

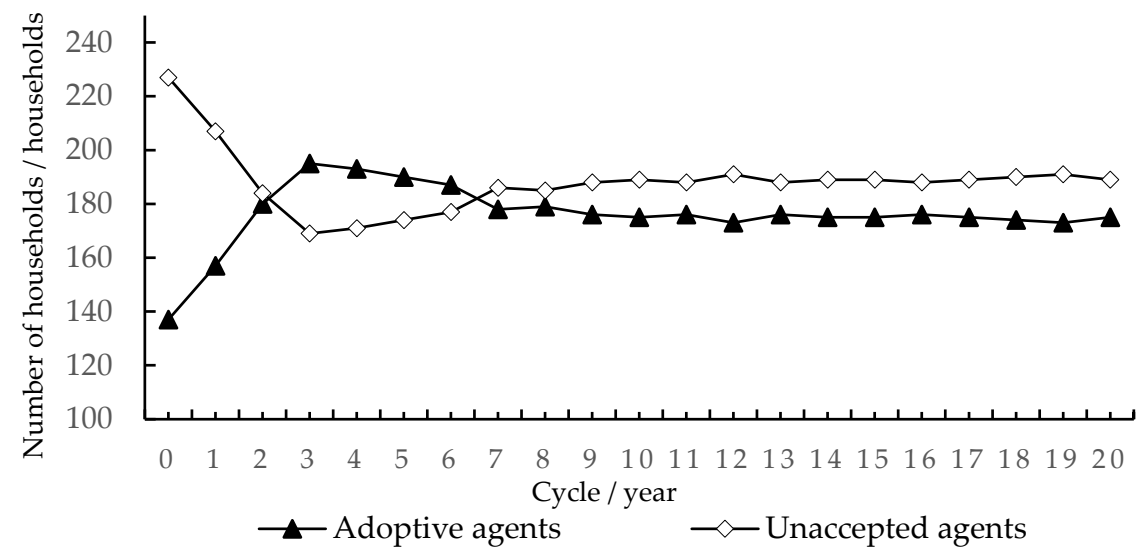

Figure 5. Dynamic process of change in quantity of agents in different periods under informationinduced policy.

Therefore, the support of an information-induced policy can promote farmers' adoption of CTT. The reason for this is that it is difficult to meet the requirements for the acceptance, learning, and understanding of new technologies due to the limitations of the age, educational level, and resources of farmers. The implementation of the policy can effectively improve the overall quality of information consumer groups and their cognition of the technical benefits, ecological benefits, and operational difficulties. Farmers with high cognition levels are more likely to demand technology. In addition, the circulation of agricultural technology information can effectively reduce the awareness of agricultural risks and effectively solve the problems in production. However, the simulation results show that an information-induced policy does not have a significant effect in the short term, and it will take at least 3 years for the policy to achieve the best effect. The implementation of an information-induced policy must be timely; it is only effective within a period of 1-3 years. Therefore, if we wish to meet the diversified information needs of farmers in different periods, governments at all levels should exploit their communication channels in order to ensure that relevant agricultural technology information is provided to farmers in a timely and efficient manner.

The following figure shows the behavior changes of three types of farmers under different policy intensities. It should be noted that the simulation results were obtained from the average value of the third cycle of the implementation of the policy intensity after several runs of the model. On the whole, with the increase in policy intensity, the number of farmers adopting CTT increased significantly. Compared with $\mathrm{P}_{2}$ farmers, the impact of the information-induced policy on $\mathrm{P}_{3}$ farmers was more significant. The behavior change in these types of farmers is more obvious, and the $P_{3}-P_{1}$ curve is steeper than the $P_{2}-P_{1}$ curve. This shows that, for $\mathrm{P}_{2}$ farmers, the impact of a belief change on their behavior is only auxiliary, and the impact of straw incineration is significant. The impact of this policy on the change in agent cognition is limited. For $\mathrm{P}_{3}$ farmers, most of them adopt a waitand-see attitude at the initial time. Under the guidance of the information-induced policy and the influence of social networks, stimulating their initial belief change can promote their proactive behavior. In detail, when the policy intensity $\mu_{1}=0-0.1$, the change in the 
number of $\mathrm{P}_{1}$ farmers is the most obvious, and the change ratio of the $\mathrm{P}_{2}-\mathrm{P}_{1}$ and $\mathrm{P}_{3}-\mathrm{P}_{1}$ curves is 2:8. At this time, mutual communication among farmers has the greatest effect on their behavior. When $\mu_{1}=0.1-1.0$, with the increase in policy intensity, the adoption of conservation tillage technology also increases. During this period, the changes in the three curves in Figure 6 (right) almost maintain a parallel trend. When the final policy continues to strengthen to 1 , the number of $\mathrm{P}_{1}$ agents reaches a peak, accounting for $52.20 \%$ of the total. The results show that the implementation of the information-induced policy has a positive impact on farmers' technology adoption behavior. With the change in policy intensity, the impact becomes increasingly obvious. Therefore, attention should be paid to the leading role of the government in communicating information about conservation tillage, improving the agricultural information service system, and filling the gap in farmers' technical information needs. In addition, information transmission among farmers is also a major factor to promote technology adoption. Farmers should carefully consider their role in information dissemination, make use of the guiding role of pilot objects, and use intuitive and efficient information dissemination methods to drive surrounding farmers to change their farming methods.

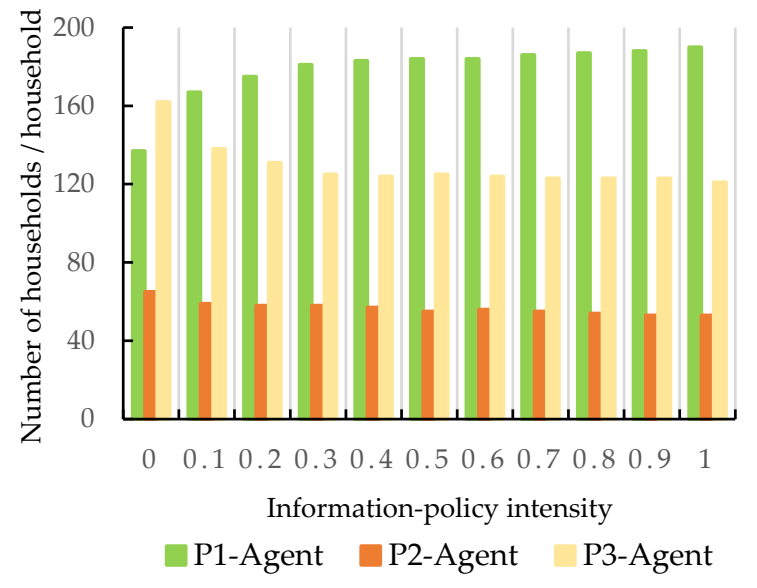

(a)

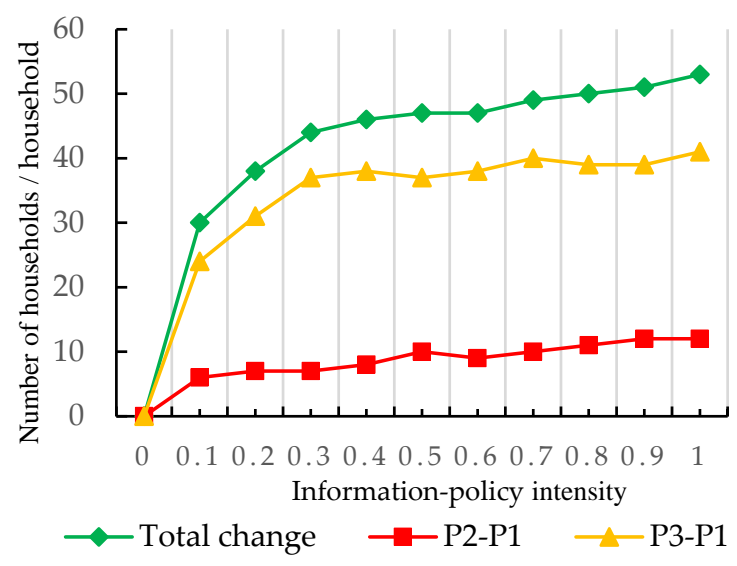

(b)

Figure 6. Dynamic changes in farmers technology adoption behaviors under information induction policies of different intensity: (a) changes in the number of farmers; (b) changes in farmers' technology adoption behaviors.

\subsection{Farmers' Decision-Making Behavior under Fund-Subsidy Policy}

Figure 7 shows that the implementation intensity of the fund-subsidy policy is $\mu_{2}=1.0$. From the changing trend of the curve, it can be seen that, over time, farmers' adoption of conservation tillage technology has undergone significant dynamic changes, and the trend line of the "adoption agent" still shows a changing trend of first increasing, then decreasing, and then becoming stable. In the $0-2$ cycle, the number of farmers adopting the conservation tillage technology increased sharply, and the behavior of 120 farmers changed, accounting for $32.97 \%$ of the total sample. Moreover, there is an intersection with the two trend lines for the first time during this period, and the number of "adopted agents" is then always higher than the number of "unaccepted agents". In the second cycle, the only "inflection point" appears in the trend line. At this time, the number of farmers adopting conservation tillage technology is the highest, nearly 252 , accounting for $69.23 \%$ of the total sample. Then, during the second to ninth weeks of the simulation operation, the "adopted agent" curve decreased rapidly in the early stage and steadily in the later stage, finally becoming stable after the ninth year. In the 9th-20th cycle, the fluctuation range of the trend line is less than 5 , and the number of agents adopting the technology is nearly 197 , accounting for $54.12 \%$ of the total sample. 


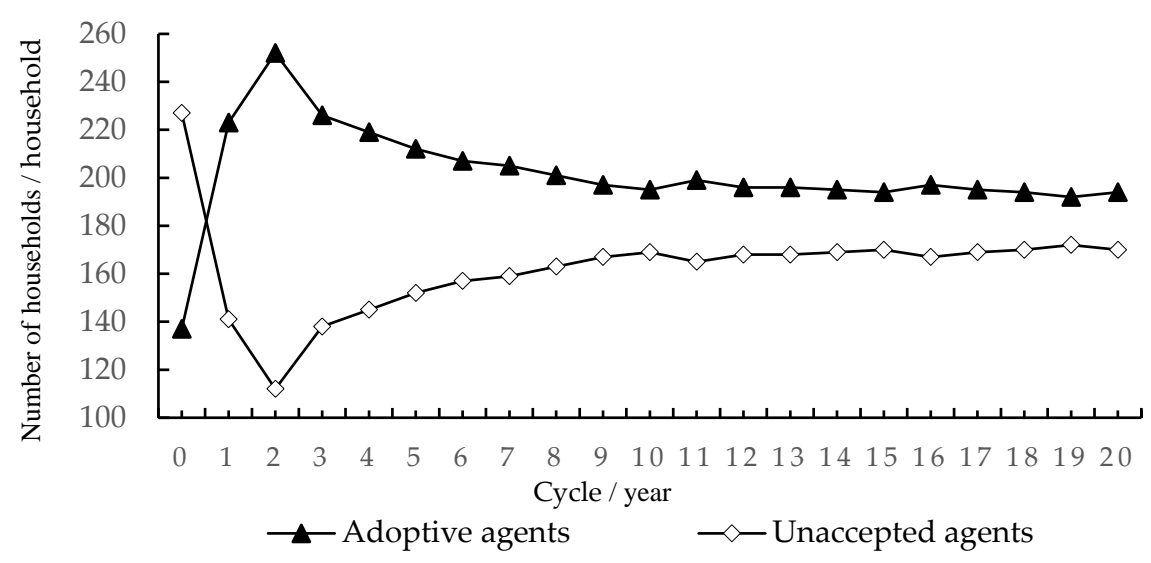

Figure 7. Dynamic process of the change in the quantity of agents in different periods under fundsubsidy policy.

Therefore, the implementation of the fund-subsidy policy has a significant impact on the adoption of CTT, but the effect of a single policy mechanism is not significant in the later stage, and such policies still have some defects. As shown in the figure, in the second year after the implementation of the fund-subsidy policy, nearly 70 farmers chose to abandon the conservation tillage technology, and, finally, nearly 167 people did not adopt conservation tillage technology. On the one hand, the policy must be implemented in a timely manner; two years later, the fund-subsidy policy is unable to meet the current needs of farmers. On the other hand, due to the simplification of designed subsidy methods, providing farmers with fixed cash subsidies is conducive to the development of policies, but the incentive effect for farmers is very limited, and they cannot meet the actual needs of all farmers. Therefore, to maintain or improve the effectiveness of the policy, the government should appoint professionals to carry out farmer censuses regularly or to dynamically observe farmers' agricultural costs and benefits and other relevant information through the big data platform, to facilitate the timely adjustment of the policies.

To explore the impact mechanism of the fund-subsidy policy on farmers' adoption of CTT in detail, the model observed the changes in their main behavior under different policy intensities. The results are shown in the figure below. The simulation results of the second cycle after the model operation were finally obtained. From the transformation of the number of entities (left of Figure 8), $\mu_{2}=0-0.1$, a small number of farmers changed their behaviors because the social network and technical information update exert an effect at this stage. When $\mu_{2}=0.1-0.4$, the numbers of three types of farmers fluctuate only slightly, indicating that the fund-subsidy policy can only alleviate the pressure of some activity costs, but it is difficult to encourage farmers to adopt the technology. When the policy intensity increases from 0.4 to 0.7 , the number of farmers who choose to adopt straw mulching technology increases rapidly, which indicates that the implementation of a fund-subsidy policy at this intensity can effectively stimulate farmers' enthusiasm for participation and successfully transfer the cost of some groups giving up straw mulching with high mechanical costs. In addition, the number of $\mathrm{P}_{1}$ agents is much larger than that of the other two agents; this demonstrates that the impact of the surrounding environment on farmers' behavior cannot be ignored. When $\mu_{2}=0.7-1.0$, the growth rate of the adopters slowed down to 247 farmers, accounting for $67.86 \%$ of the total sample.

From the behavior change of heterogeneous agents (right in Figure 8), the three curves maintain an upward trend, but there are obvious differences in the range of change. According to the $\mathrm{P}_{2}-\mathrm{P}_{1}$ curve, there is a slow and steady upward trend. When the policy intensity is 1 , the curve reaches the highest point, and $38.46 \%$ of such agents change their technology adoption behaviors. According to the $\mathrm{P}_{3}-\mathrm{P}_{1}$ curve, the curve change path is consistent with the "total change" curve. At the peak of the curve, nearly $47.53 \%$ of $\mathrm{P}_{3}$ farmers changed to $P_{1}$. When the "total change" curve reaches the peak, the proportion of $\mathrm{P}_{2}$ and $\mathrm{P}_{3}$ agents is $22.73 \%$ and $77.27 \%$, indicating that $\mathrm{P}_{3}$ farmers are more sensitive to 
subsidy policies. In conclusion, there are obvious differences in farmers' behavior changes under different fund-subsidy policy intensities. Therefore, the government should be more flexible when formulating relevant fund-subsidy policies. The "one size fits all" compensation standard cannot meet the interest demands of all farmers. According to the simulation results, when the policy intensity is between 0.4 and 0.7 , the efficiency of mobilizing the change in agent behavior is the best. In addition, there are obvious differences in the responses of farmers to the policy. Therefore, dynamic fund-subsidy policies should be formulated pertinently and flexibly to avoid overly unified subsidy standards.

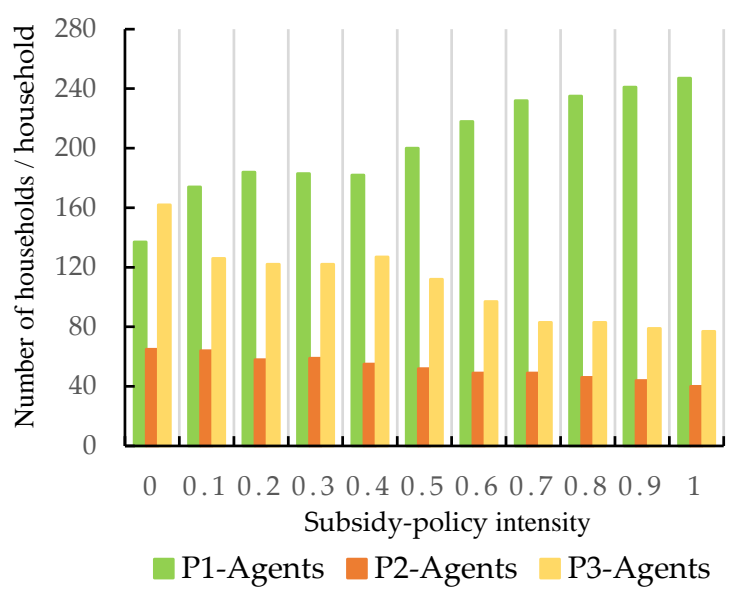

(a)

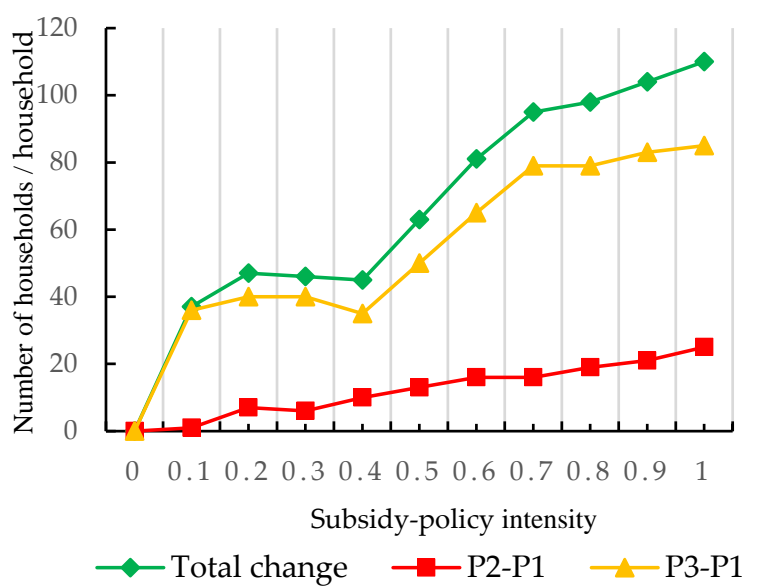

(b)

Figure 8. Dynamic changes in farmers' technology adoption behaviors under fund-subsidy policies of different intensity: (a) changes in the number of farmers; (b) changes in farmers' technology adoption behaviors.

\subsection{Farmers' Decision-Making Behavior under Control-Constrained Policy}

The implementation intensity of the control-constrained policy is $\mu_{3}=1.0$, and the change in farmers' decision-making behavior is shown in Figure 9. Similar to the curve change trend under the above two scenarios, the "adoption agent" curve presents a change process of first increasing, then decreasing, then becoming stable. Specifically, during the 0-2 cycle of the model, the number of farmers adopting CTT increased sharply and exceeded the number of farmers not adopting CTT. In the second cycle, the curve reached the "peak". At this time, the number of farmers adopting CTT was the highest, nearly 217, accounting for $59.62 \%$ of the total sample. In the second to seventh years of the simulation operation, the number of adopters decreased by a stable range of 8 to 10, and finally fluctuated within the same range in the seventh to twentieth years. At this time, the number of adopters was nearly 187 , accounting for $51.37 \%$ of the total sample. The simulation results show that the control-constrained policy has a significant impact on farmers' use of CTT in 1-2 years, but the effect gradually decreases after the second year. This shows that such policies are still time-effective, and some results can be achieved under the control of fines, monitoring, and the control of farmers in the short term; however, in the long term, there are still some farmers with no substantive and fundamental changes in their behavior.

Furthermore, we explored the impact of policy intensity on farmers' technology adoption behavior. The simulation results of the main decision-making behavior in cycle 2 are shown in the Figure 10. On the whole, with the increase in the policy implementation intensity, the number of $P_{1}$ agents increased steadily, and the number of $P_{2}$ agents and $P_{3}$ agents decreased, indicating that the strengthening of policy implementation has a positive impact on the policy's effect. Policy intensity implementation $\mu_{3}=0.1-1.0$, and for every 0.1 increase in policy implementation, the average number of farmers adopting CTT increased steadily by 8 . In the dynamic situation of farmers' behavior, when $\mu_{3}=0.1-0.3$, the three 
curves have no obvious fluctuation. When the policy intensity is strengthened from 0.3 to 1.0 , the change range of farmers' behavior also increases. When $\mu_{3}=1.0,50.77 \%$ of $P_{2}$ farmers chose to adopt CTT, and $31.48 \%$ of $\mathrm{P}_{3}$ farmers changed their behavior. It is known that the control-constrained policy is targeted, and it changes the "belief" and "desire" of $\mathrm{P}_{2}$ agents, but it is ultimately still unable to eliminate the phenomenon of straw burning. According to the simulation results, nearly $50 \%$ of farmers did not adopt conservation tillage. Even under policy vigilance and financial constraints, farmers still chose straw incineration, abandonment, and other treatment methods.

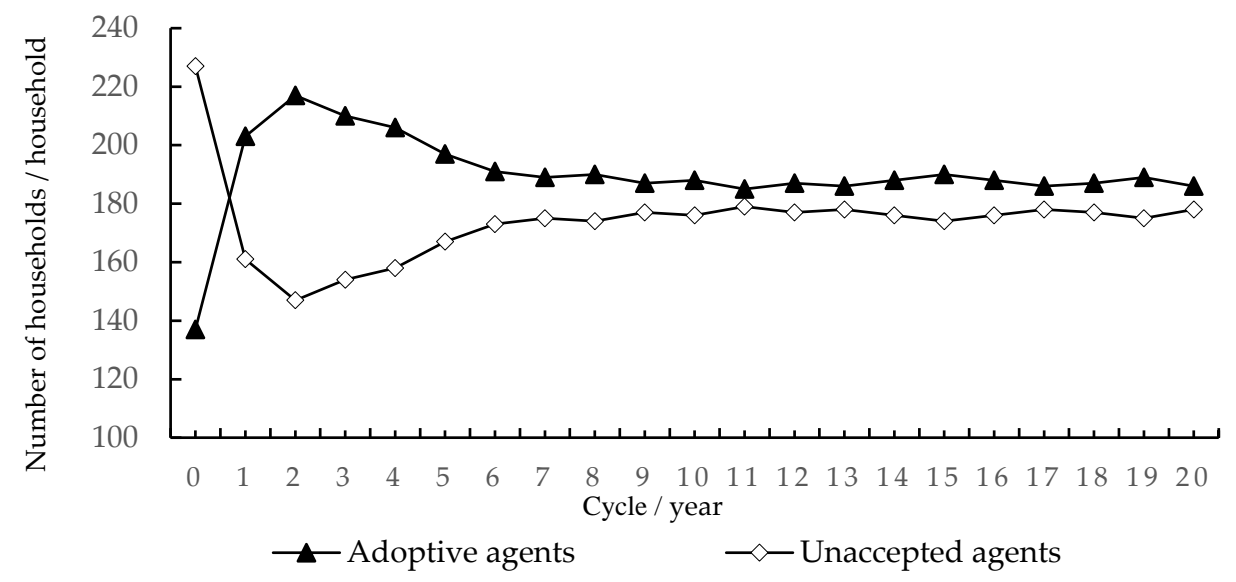

Figure 9. Dynamic process of the change in the quantity of agents in different periods under controlconstrained policy.

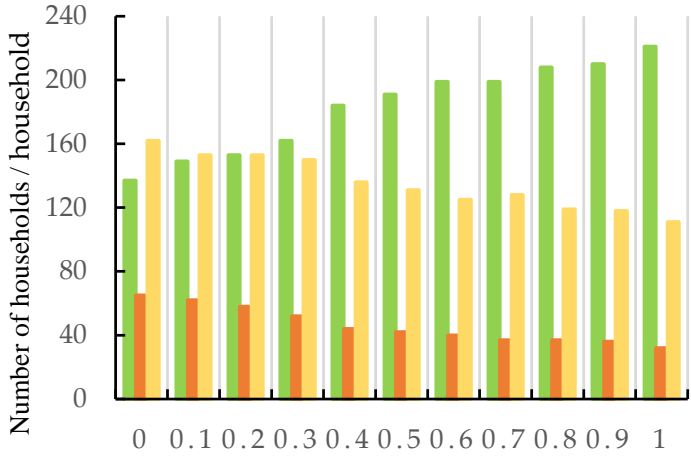

Punishment-policy intensity

P1-Agents $\square$ P2-Agents $\square$ P3-Agents

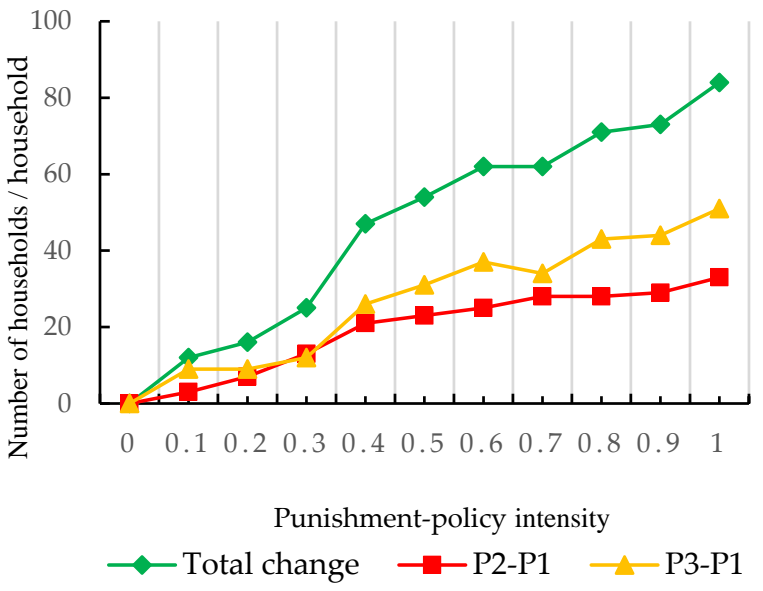

(b)

(a)

Figure 10. Dynamic changes in farmers technology adoption behaviors under regulatory constraints of different intensity: (a) changes in the number of farmers; (b) changes in farmers' technology adoption behaviors.

The reason for the above is that the policy implementation measures are too formal. It is necessary to pay attention to the effectiveness of the implementation of control and restraint policies. Most of the existing policies involve the surface management of farmers, i.e., "treating the symptoms but not the root cause". When the government issues orders or instructions with too little punishment, on the one hand, farmers' cultural literacy, low awareness of environmental protection, and blocked access to information limit their technology choices. Most of them choose to ignore warnings and slogans, resulting in a lack of participation in low-intensity control policies. On the other hand, taking the straw returning technology as an example, farmers in Northeast China have a large annual straw output and spend a great deal of money to dispose of straw, which reduces the economic 
benefits. Due to the high operation cost and great technical difficulty, even if farmers fully realize the importance of conservation tillage and the seriousness of straw burning, to maximize their benefits, they must bear the cost of fines; local incineration will also be selected. Therefore, the use of mild punishments does not ensure farmers' awareness of the seriousness of the situation.

\subsection{Summary of Results}

According to the above results, the three types of policy tools, namely "informationinduced", "fund-subsidy", and "control-constrained", have markedly different effects on the adoption of protective farming techniques by farmers under different implementation intensities. In terms of the time characteristics of the policy tools, when the unified intensity of the three types of policy tools is 1.0, farmers' behavior changes are the same on the whole, and the number of farmers adopting conservation tillage technology shows a trend of first increasing, then decreasing, then becoming stable. In detail, there are differences in the time-effectiveness of the policy tools. The information-induced policy is most effective only in the third year, which is one year later than the other two types of policy tools. After the 9th year, the fund-subsidy policy has a stable effect, which is two years longer than the other two types of policy tools. In terms of the characteristic of policy implementation intensity, the effects of the three types of policy tools on farmers' technology adoption behaviors vary. For information-induced policies, the higher the intensity, the stronger the effect, showing a steady upward trend. For the fund-subsidy policy, the effect of the impact presents a trend of rapid growth initially, followed by slow growth. When the intensity is between 0.4 and 0.7 , the effect of changes in farmers' behavior is the best. Regarding control-constrained policies, they tend to have small effects in the early stage and larger effects in the later stage. When the three types of policy tools achieve the best impact, the numbers of farmers adopting CTT are 190, 247, and 221, respectively. The specific situation is shown in Table 6.

Table 6. Comparison of simulation results.

\begin{tabular}{|c|c|c|c|c|c|c|}
\hline \multirow[b]{2}{*}{ Type } & \multicolumn{3}{|c|}{ Time Characteristics } & \multicolumn{3}{|c|}{ Strength Characteristics } \\
\hline & Features & Timeliness & $\begin{array}{l}\text { Stationary } \\
\text { Period }\end{array}$ & Features & $\begin{array}{l}\text { Optimal } \\
\text { Strength }\end{array}$ & $\begin{array}{l}\text { Optimal } \\
\text { Strength } \\
\text { Utility }\end{array}$ \\
\hline $\begin{array}{l}\text { Information- } \\
\text { induced }\end{array}$ & $\begin{array}{c}\text { Increase first, } \\
\text { decrease }\end{array}$ & $\begin{array}{l}\text { One to three } \\
\text { years }\end{array}$ & Seven years later & $\begin{array}{l}\text { The effect gradually increases } \\
\text { with intensity }\end{array}$ & 1.0 & 190 adopters \\
\hline Fund-subsidy & then stabilize & $\begin{array}{l}\text { One to two } \\
\text { years }\end{array}$ & Nine years later & $\begin{array}{l}\text { The effect is multiplied by the } \\
\text { and the slow increase trend in the } \\
\text { later stage }\end{array}$ & $0.4-0.7$ & 247 adopters \\
\hline $\begin{array}{l}\text { Control- } \\
\text { constrained }\end{array}$ & & $\begin{array}{l}\text { One to two } \\
\text { years }\end{array}$ & Seven years later & $\begin{array}{l}\text { As the intensity increases, the } \\
\text { utility is smaller in the early stage } \\
\text { and larger in the later stage }\end{array}$ & $>0.3$ & 247 adopters \\
\hline
\end{tabular}

\section{Conclusions and Discussion}

In this study, we construct a theoretical framework of farmers' adoption behaviors towards CTT, based on the Agent BDI model, using survey data of Liaoning Province, and taking the straw mulching technology as an example; we also apply the NetLogo simulation platform to simulate the complex, dynamic effects of policy tools on farmers' adoption of CTT. The results show that (1) the three policy tools, namely information-induced, fund-subsidy, and control-constrained, have a positive impact on farmers' decision-making behavior. These three types of policy tools are all time-sensitive. Within 2-3 years of implementing the policy, the number of farmers adopting CTT will reach the maximum. However, over time, the effect is significantly weakened. and stabilizes in the 7th or 9th year. (2) The greater the intensity of the implementation of the information-induced policy, the steadier the increase in the number of farmers adopting CTT. This shows that changing the subject's beliefs and eliminating the constraints of personal characteristics and resource 
factors can continue to have a significant positive impact on farmers' decision-making behavior. Regarding the fund-subsidy policy, when the government subsidy amount is between $40 \%$ and $70 \%$ of the operating cost, the agent's "belief" and "desire" change at the same time, and the main body's response is most notable; the policy continues to increase, but the impact of continued policy intensity slows down. For control-constrained policies, when the penalty amount is higher than $30 \%$ of the operating costs, the effect is more significant. The impact of policy stimulus on the agents of farmers is different. (3) For straw burning farmers, the significance of the policy response effect is "control-constrained $>$ fund-subsidy > information-induced"; for farmers who use straw mulching, the response effect is in the order of "fund-subsidy > control-constrained > information-induced".

The above conclusions confirm the hypothesis of this study that policy tools have a positive impact on farmers' adoption of CTT, but the impacts are not the same. The following policy insights can be obtained: first, attention should be paid to the positive role of the information-induced policy, and farmers' limitations regarding technical information knowledge should be eliminated. Local agricultural service publicity departments should deliver agricultural technical information to farmers in a timely and efficient manner, fill in the agricultural information gaps via multiple channels and methods, guide peasants to dialectically assess conservation agriculture, and change farmers' traditional farming thinking. Second, it is necessary to improve and refine the fund-subsidy policy mechanism to reduce the limitations of farmers' breeding costs. To increase farmers' enthusiasm for conservation farming, combined with local farming conditions, it is necessary to establish a diversified compensation standard, appropriately increase the number of subsidies, and establish a targeted differentiation policy mechanism for subsidies, so that farmers are less affected by resource and production cost constraints. Third, it is necessary to implement and strengthen control policies and substantively guide farmers to participate in the transformation of breeding technology. The effective combination of government supervision and social supervision will strengthen the governance and control capabilities of local governments and intuitively increase awareness of education-related laws. It is crucial to stablish and clarify policies and punishment standards, combine modern advanced technology, and appropriately control farmers' behavior.

This study also has some limitations, which might open up avenues for future research. First, the research results show that the CTT adoption behavior of farmers is dynamically affected by various policy tools, but in reality, the change in farmers' behavior is not affected by a single policy tool. Therefore, it is necessary to strengthen the mixed research of policy tools and analyze their impact and effectiveness in depth. Second, the research only emphasizes the primary quantification of policy characteristics, because policy formulation is a relatively complex process, accompanied by high administrative costs, human resources, and material resources. Therefore, expanding the model to establish a direct connection with the real situation, strengthen the rationality of policy tool design, and obtain a more scientific policy standard are areas that need further research in the future. Third, this study uses three policy tools to examine scenarios to explore farmers' technology adoption behavior, and there are limitations in the choice of policy tools and simulation models. Specifically, policy tools have a positive impact on farmers' adoption of CTT. However, this study finds that policy tools have obvious effects only in the short term. Therefore, the effects of long-term policy tools need to be explored, and it is necessary to strengthen mixed research on policy tools to obtain more scientific policy standards. These are additional areas that need to be further explored in the future.

Author Contributions: Conceptualization, H.L. and Y.W.; Formal Analysis, H.L. and M.W.; Data Curation, H.L. and X.L. (Xinhua Liu); Methodology, H.L. and J.G.; Writing-Review and Editing, Y.W., X.L. (Xiaojuan Luo) and H.L. All authors have read and agreed to the published version of the manuscript.

Funding: This research was funded by the National Natural Science Foundation of China (72074153, 72063019 and 71773054). 
Institutional Review Board Statement: Not applicable.

Informed Consent Statement: Not applicable.

Data Availability Statement: The data presented in this study are available on request from the corresponding author. The data are not publicly available due to privacy restrictions.

Acknowledgments: We are grateful to the editors and three anonymous reviewers for their constructive comments and suggestions.

Conflicts of Interest: The authors declare no conflict of interest.

\section{References}

1. Li, W.; Feng, T.T.; Hao, J.M. The evolving concepts of land administration in China: Cultivated land protection perspective. Land Use Policy 2009, 26, 262-272. [CrossRef]

2. Liu, X.W.; Zhao, C.L.; Song, W. Review of the evolution of cultivated land protection policies in the period following China's reform and liberalization. Land Use Policy 2017, 67, 660-669. [CrossRef]

3. Chavez, A.B.; Perz, S.G. Adoption of policy incentives and land use: Lessons from frontier agriculture in southeastern peru. Hum. Ecol. 2012, 40, 525-539. [CrossRef]

4. Wang, Z.T.; Liu, L.; Chen, Q.; Wen, X.X.; Liao, Y.C. Conservation tillage increases soil bacterial diversity in the dryland of northern China. Agron. Sustain. Dev. 2016, 36, 28. [CrossRef]

5. He, J.; Li, H.W.; Wang, Q.J.; Gao, H.W.; Li, W.Y.; Zhang, X.M.; McGiffen, M. The adoption of conservation tillage in China. Ecol. Complex. Sustain. 2010, 1195, 96-106. [CrossRef]

6. Derpsch, R.; Franzluebbers, A.J.; Duiker, S.W.; Reicosky, D.C.; Koeller, K.; Friedrich, T.; Sturny, W.G.; Sa, J.C.M.; Weiss, K. Why do we need to standardize no-tillage research? Soil Tillage Res. 2016, 137, 16-22. [CrossRef]

7. Liu, B.B.; Wu, Q.R.; Wang, F.; Zhang, B. Is straw return-to-field always beneficial? Evidence from an integrated cost-benefit analysis. Energy 2019, 171, 393-402. [CrossRef]

8. Zhang, S.X.; Li, Q.; Zhang, X.P.; Wei, K.; Chen, L.J.; Liang, W.J. Effects of conservation tillage on soil aggregation and aggregate binding agents in black soil of Northeast China. Soil Tillage Res. 2012, 124, 196-202. [CrossRef]

9. He, J.; Li, H.W.; Kuhn, N.J.; Wang, Q.J.; Zhang, X.M. Effect of ridge tillage, no-tillage, and conventional tillage on soil temperature, water use, and crop performance in cold and semi-arid areas in Northeast China. Aust. J. Soil Res. 2010, 48, 737-744. [CrossRef]

10. Pedersen, A.B.; Nielsen, H.O.; Christensen, T.; Hasler, B. Optimising the effect of policy instruments: A study of farmers' decision rationales and how they match the incentives in Danish pesticide policy. J. Env. Plamning Manag. 2012, 55, 1094-1110. [CrossRef]

11. Xu, X.M.; Zheng, F.L.; Wilson, G.V.; He, C.; Lu, J.; Bian, F. Comparison of runoff and soil loss in different tillage systems in the Mollisol region of Northeast China. Soil Tillage Res. 2018, 177, 1-11. [CrossRef]

12. Pannell, D.J.; Claassen, R. The Roles of Adoption and Behavior Change in Agricultural Policy. Appl. Econ. Perspect. Policy 2020, 4, 31-41. [CrossRef]

13. Liu, M.; Wu, L.H.; Gao, Y.; Wang, Y.H. Farmers' adoption of sustainable agricultural technologies: A case study in Shandong Province, China. J. Food Agric. Envirment 2011, 9, 623-628.

14. Kaine, G.; Young, J.; Lourey, R.; Greenhalgh, S. Policy choice framework: Guiding policy makers in changing farmer behavior. Ecol. Soc. 2017, 22, 2. [CrossRef]

15. Madarasz, B.; Jakab, G.; Szalai, Z.; Juhos, K.; Kotroczo, Z.; Toth, A.; Ladanyi, M. Long-term effects of conservation tillage on soil erosion in Central Europe: A random forest-based approach. Soil Tillage Res. 2021, 209, 29-43. [CrossRef]

16. Dai, Z.J.; Hu, J.S.; Fan, J.; Fu, W.; Wang, H.; Hao, M.D. No-tillage with mulching improves maize yield in dryland farming through regulating soil temperature, water and nitrate-N. Agric. Ecosyst. Environ. 2021, 309, 107288. [CrossRef]

17. Ntshangase, N.L.; Muroyiwa, B.; Sibanda, M. Farmers' Perceptions and Factors Influencing the Adoption of No-Till Conservation Agriculture by Small-Scale Farmers in Zashuke, KwaZulu-Natal Province. Sustainability 2018, 10, 555. [CrossRef]

18. Grabowski, P.P.; Kerr, J.M. Resource constraints and partial adoption of conservation agriculture by hand-hoe farmers in Mozambique. Int. J. Agric. Sustain. 2014, 12, 37-53. [CrossRef]

19. Carlisle, L. Factors influencing farmer adoption of soil health practices in the United States: A narrative review. Agroecol. Sustain. Food Syst. 2016, 4, 583-613. [CrossRef]

20. Mann, S. Conservation by Innovation: What Are the Triggers for Participation among Swiss Farmers? Ecol. Econ. 2018, 146, 10-16. [CrossRef]

21. Hou, D.Y.; Ding, Z.Y.; Li, G.H.; Wu, L.H.; Hu, P.J. A Sustainability Assessment Framework for Agricultural Land Remediation in China. Land Degration Dev. 2018, 29, 1005-1018. [CrossRef]

22. Schieffer, J.; Dillon, C. The economic and environmental impacts of precision agriculture and interactions with agro-environmental policy. Precis. Agric. 2016, 16, 46-61. [CrossRef]

23. Wu, Y.Z.; Shan, L.P.; Guo, Z.; Peng, Y. Cultivated land protection policies in China facing 2030: Dynamic balance system versus basic farmland zoning. Habitat Int. 2017, 69, 126-138. [CrossRef]

24. Kuang, B.; Han, J.; Lu, X.H.; Zhang, X.P.; Fan, X.Y. Quantitative evaluation of China's cultivated land protection policies based on the PMC-Index model. Land Use Policy 2020, 99, 105062. [CrossRef] 
25. Liao, C.N.; Chen, Y.J.; Tang, C.S. Information Provision Policies for Improving Farmer Welfare in Developing Countries: Heterogeneous Farmers and Market Selection. MSom-Manuf. Serv. Oper. Manag. 2019, 21, 254-270. [CrossRef]

26. Brendan, B.; Ian, N.; Rick, L. Constraints to the utilisation of conservation agriculture in Africa as perceived by agricultural extension service providers. Land Use Policy 2018, 73, 331-340.

27. Pan, Y.; Wu, J.X.; Zhang, Y.J.; Zhang, X.Z.; Yu, C.Q. Simultaneous enhancement of ecosystem services and poverty reduction through adjustments to subsidy policies relating to grassland use in Tibet, China. Ecosyst. Serv. 2021, 48, 101254. [CrossRef]

28. Barry, L.E.; Yao, R.T.; Harrison, D.R.; Paragahawewa, U.H.; Pannell, D.J. Enhancing ecosystem services through afforestation: How policy can help. Land Use Policy 2014, 39, 135-145. [CrossRef]

29. Yadav, D.; Vishwakarma, A.K.; Sharma, N.K.; Biswas, A.K.; Ojasvi, P.R.; Kumar, D.; Kumawat, A.; Singh, D. Sustaining the properties of black soil in Central India through crop residue management in a conservation-agriculture-based soybean-wheat system. Land Degrad. Dev. 2021, 32, 2906-2921. [CrossRef]

30. Aregay, F.A.; Zhao, M.J.; Xu, T. Knowledge, attitude and behavior of farmers in farmland conservation in China: An application of the structural equation model. J. Environ. Plan. Manag. 2018, 6, 249-271. [CrossRef]

31. Deng, J.; Sun, P.S.; Zhao, F.Z.; Han, X.H.; Yang, G.H.; Feng, Y.Z. Analysis of the ecological conservation behavior of farmers in payment for ecosystem service programs in eco-environmentally fragile areas using social psychology models. Sci. Total Environ. 2016, 550, 382-390. [CrossRef] [PubMed]

32. Malawska, A.; Topping, C.J. Evaluating the role of behavioral factors and practical constraints in the performance of an agentbased model of farmer decision making. Agric. Syst. 2016, 143, 136-146. [CrossRef]

33. Huang, S.Y.; Hu, G.P.; Chennault, C.; Su, L.; Brandes, E.; Heaton, E.; Schulte, L.; Wang, L.Z.; Tyndall, J. Agent-based modeling of bioenergy crop adoption and farmer decision-making. Energy 2016, 115, 1188-1201. [CrossRef]

34. Valbuena, D.; Verburg, P.H.; Bregt, A.K.; Ligtenberg, A. An agent-based approach to model land-use change at a regional scale. Landsc. Ecol. 2010, 25, 185-199. [CrossRef]

35. Morgan, F.J. Daigneault, A.J. Estimating Impacts of Climate Change Policy on Land Use: An Agent-Based Modelling Approach. PLoS ONE 2015, 10, 127317. [CrossRef]

36. Pakravan, M.H.; MacCarty, N. An Agent-Based Model for Adoption of Clean Technology Using the Theory of Planned Behavior. J. Mech. Des. 2021, 143, 21402. [CrossRef]

37. Singh, D.; Padgham, L.; Logan, B. Integrating BDI Agents with Agent-Based Simulation Platforms. Auton. Agents Multi-Agent Syst. 2016, 30, 1050-1071. [CrossRef]

38. Mehryar, S.; Sliuzas, R.; Schwarz, N.; Sharifi, A.; van Maarseveen, M. From individual Fuzzy Cognitive Maps to Agent Based Models: Modeling multi-factorial and multi-stakeholder decision-making for water scarcity. J. Environ. Manag. 2019, $250,109482$. [CrossRef] [PubMed]

39. Mao, H.; Chai, Y.J.; Chen, S.J. Land Tenure and Green Production Behavior: Empirical Analysis Based on Fertilizer Use by Cotton Farmers in China. Int. J. Environ. Res. Public Health 2021, 18, 4677. [CrossRef] [PubMed]

40. Casali, A.; Godo, L.; Sierra, C. A graded BDI agent model to represent and reason about preferences. Artif. Intell. 2011, 175, 1468-1478. [CrossRef]

41. Su, C.; Li, H.G. An affective learning agent with Petri-net-based implementation. Appl. Intell. 2012, 37, 569-585. [CrossRef]

42. Tian, G.J.; Ouyang, Y.; Quan, Q.A.; Wu, J.G. Simulating spatiotemporal dynamics of urbanization with multi-agent systems-A case study of the Phoenix metropolitan region, USA. Ecol. Model. 2011, 222, 1129-1138. [CrossRef]

43. Liang, X.Y.; Chen, H.; Wang, Y.N.; Song, S.X. Design and application of a CA-BDI model to determine farmers' land-use behavior. Springerplus 2016, 5, 1581. [CrossRef] [PubMed]

44. Schmid, A.A. The Spartan School of Institutional Economics at Michigan State University. Res. Hist. Econ. Thought Methodol. 2002, $22,207-243$.

45. Rutherford, M. American Institutional Economics in the Interwar Period; Blackwell Publishing Ltd.: Hoboken, NJ, USA. [CrossRef]

46. Ye, Y.; Fang, X.Q. Land use change in Northeast China in the twentieth century: A note on sources, methods and patterns. J. Hist. Geogr. 2009, 35, 311-329. [CrossRef]

47. Li, W.B.; Wang, D.Y.; Liu, S.H.; Zhu, Y.L.; Yan, Z.R. Reclamation of Cultivated Land Reserves in Northeast China: Indigenous Ecological Insecurity Underlying National Food Security. Int. J. Environ. Res. Public Health 2020, 17, 1211. [CrossRef]

48. Qian, F.K.; Chi, Y.R.; Lal, R. Spatiotemporal characteristics analysis of multifunctional cultivated land: A case-study in Shenyang, Northeast China. Land Degrad. Dev. 2020, 31, 1812-1822. [CrossRef]

49. Thiele, J.C.; Grimm, V. NetLogo meets R: Linking agent-based models with a toolbox for their analysis. Environ. Model. Softw. 2010, 25, 972-974. [CrossRef]

50. Niazi, M.; Hussain, A. Agent-Based Tools for Modeling and Simulation of Self-Organization in Peer-to-Peer, Ad Hoc, and Other Complex Networks. IEEE Commun. Mag. 2009, 47, 166-173. [CrossRef]

51. Rebaudo, F.; Rouzic, A.L.; Dupas, S.; Silvain, J.F.; Harry, M.; Dangles, O. SimAdapt: An individual-based genetic model for simulating landscape management impacts on populations. Methods Ecol. Evol. 2013, 4, 595-600. [CrossRef]

52. Banitz, T.; Gras, A.; Ginovart, M. Individual-based modeling of soil organic matter in NetLogo: Transparent, user-friendly, and open. Environ. Model. Softw. 2015, 71, 39-45. [CrossRef]

53. Wang, H.Z.; Mostafizi, A.; Cramer, L.A.; Cox, D.; Park, H. An agent-based model of a multimodal near-field tsunami evacuation: Decision-making and life safety. Transp. Res. Part C-Emerg. Technol. 2016, 64, 86-100. [CrossRef] 
54. Li, H.; Dai, M.; Dai, S.L.; Dong, X.J. Current status and environment impact of direct straw return in China's cropland-A review. Ecotoxicol. Environ. Saf. 2018, 159, 293-300. [CrossRef] [PubMed]

55. Hong, J.L.; Ren, L.J.; Hong, J.M.; Xu, C.Q. Environmental impact assessment of corn straw utilization in China. J. Clean. Prod. 2016, 112, 1700-1708. [CrossRef] 